Article

\title{
Linking Group Theory to Social Science Game Theory: Interaction Grammars, Group Subcultures and Games for Comparative Analysis
}

\author{
Tom R. Burns ${ }^{1,2, *}$, Ewa Roszkowska ${ }^{3}$, Ugo Corte $^{1}$ and Nora Machado Des Johansson ${ }^{2}$ \\ 1 Department of Sociology, University of Uppsala, Uppsala 75126, Sweden; ugo.corte@gmail.com \\ 2 Lisbon University Institute (ISCTE), Lisbon 1649-026, Portugal; noramachado@gmail.com \\ 3 Faculty of Managements and Economics, University of Bialystok, Bialystok 15-062, Poland; erosz@o2.pl \\ * Correspondence: tom.burns@soc.uu.se; Tel.: +46-18-471-5178
}

Received: 10 April 2017; Accepted: 29 August 2017; Published: 7 September 2017

\begin{abstract}
This article draws on earlier work in social system theorizing and analysis-in particular, the theory of social rule systems. On the basis of this foundational work, its aim is to systematically link theories of social groups and organizations, on the one hand, and social science game and interaction theory, on the other hand. Rule system theory has contributed to significant features of group theory and social science game theory. It is a cultural-institutional approach to conceptualizing group systems and games. We explore how groups and their particular games can be effectively described, analyzed, and compared-and their similarities and differences identified on a systematic basis. For illustrative purposes, we present a selection of several ideal types of groups: a military unit, a terrorist group, a recreational or social group, a research group, and a business entity, each of whom has a distinct rule configuration making for particular "rules of the game" and game patterns of interaction and outcome.
\end{abstract}

Keywords: social science game theory; interaction grammars; groups; games; rule configuration; rule system compatibility; structuring

\section{Group Theory, Game Theory, and Their Interlinkage: An Overview}

\subsection{Introduction}

Group theory derives from the theory of social rules and rule complexes applied to describing, analyzing, and explaining diverse types of groups and organizations and their particular patterns of behavior. The theory conceptualizes group interaction grammars as rule regimes that structure and regulate social relationships and interaction patterns in any given group or organization: (1) It states that the grammars are complexes of rules applying to institutionalized relationships and interactions of individuals, groups, and organizations; (2) The research conceptualizes and applies rules and rule complexes and their derivatives with respect to roles, role relationships, norms, group procedures and production functions and their performances; (3) it identifies a finite and universal set of rule categories (10) making up a rule regime (a major subsystem of any functioning group, organization, or community); (4) the theory conceptualizes particular "group rule configurations"-rule regimes for any given group with specified, more or less compatible rules in the universal rule categories; (5) groups are identifiable as well as differentiable by their particular rule configurations (as well as by their resource and agency bases). The article emphasizes the differentiating character of any given group's distinct rule configuration or sub-culture-the actual complex of rules guiding and regulating behavior in any given group. Groups are distinguishable (and comparable) in terms of the content of their finite rule categories: rules concerning group identity, purposes, social relations, 
production algorithms, internal and external governance, time and place rules. Groups may change rules in their configuration in response to external and/or internal changes, pressures, incentives, performance failings.

Social science game theory (SGT) is based on the formulation of a theory of rules and rule systems with a systematic grounding in contemporary social sciences. Sociological concepts such as norm, value, belief, role, social relationship, and institution can be defined in a uniform way in SGT in terms of rules, complexes of rules, and rule regimes. Group rule configurations provide a conceptual linkage between group theory and game theory. They are the core of "rules of the game" and the rule-based patterning of interactions and outcomes for different types of groups. The theory is applied to games such as classical games (e.g., cooperative and non-cooperative games, PD games, zero-sum games, etc.) At the same time, the theory is applicable to non-strategic situations, in particular routine, institutionalized interactions (many role interactions are of this sort), rituals, ceremonies-with little or no significant decisions or choice activities.

\subsection{Rule Regimes, Group Properties (Relations/Structures), and Group Differentiation}

In this section, the theory of social rules and rule regimes is applied to group theory for describing, analyzing, and explaining diverse types of groups. (As indicated above, the same theory is also used in the formulation of a social science game theory. ${ }^{1}$ ) Rule system theory provides a model which identifies key specific rule categories which underlie or, when enacted, generate particular group or organizational properties and patterns: the rules concern a group's particular participants and their relations and social structure, its times and places, its values and goals, its activities and procedures and productions, its materials and technologies used in group activities and production functions. They concern the finite and universal rule base of group social action and interaction, its material, social structural, and agential conditions.

The rule regime conceptualization is a basis to describe, differentiate, and explain groups (consisting of collective identity membership, social structure, particular patterns of activities, and outputs (products, types of performance, developments)).

\subsubsection{Rule Regimes and Social Relations/Structures}

Most human social activity - in all of its extraordinary variety - is organized and regulated by socially produced and reproduced rules and systems of rules (Burns and Flam 1987; Giddens 1984; Harre 1979). ${ }^{2}$ Such rules are not transcendental abstractions. Rule regimes are carried, applied, adapted, and transformed by concrete human agents (individuals, groups, and communities)—in their language, customs

1 The main goal of the article is not, however, presentation of strict mathematical tools "for modeling behaviour of diverse groups" and technical formalization; rather, it provides the conceptual, methodological and descriptive foundations for such modelling. However, we have accomplished some technical formalization. One of our collaborators, Anna Gomolinska has developed "technical machinery" such as soft applicability of rules, as well granular computing (Gomolinska 2008, 2002). Gomolinska (2005) studied soft applicability of rules (including decision rules) within the framework of rough approximation spaces. Such a form of rule applicability, called rough applicability, is based on various kinds of rough satisfiability of sets of rule premises, where granulation of information plays an important role. Gomolinska (2010) has presented the rough granular view on the problem of satisfiability of formulas (defining some conditions) by objects under incomplete information about the objects and the situation. Judgement of formula satisfiability is important, e.g., when making the decision whether or not to apply a rule to an object. Data granulation and granular computing are some of the methods for modelling and processing imprecise and uncertain data. In general, granular computing can be viewed as: (i) a method of structured problem solving; (ii) a paradigm of information processing; and (iii) a way of structured thinking (Skowron and Jankowski 2016; Skowron et al. 2016; Loia et al. 2016).

2 In the social science literature a standard distinction is made between formal and informal rules. Formal rules are found in sacred books, legal codes, handbooks of rules and regulations, or in the design of organizations or technologies. Informal rules, in contrast, are generated and reproduced in ongoing interactions-they appear more spontaneous, although they may be underwritten by iron conduct codes. The extent to which the formal and informal rule systems diverge or contradict one another varies. Numerous organizational studies have revealed that official, formal rules are seldom those that operate in practice (Burns and Flam 1987). More often than not, the informal unwritten rules not only contradict formal rules but in many instances take precedence over them, governing organizational life. 
and codes of conduct, norms, and laws and in the social institutions of the modern world, including family, community, market, business enterprises and government agencies. The agents interact, exchange, struggle, and exercise power in their particular group and organizational contexts, in large part based on the rule regimes regulating them and which they maintain, adapt, and transform.

The making, interpretation, and implementation of social rules are universal in human societies, as are their reformulation and transformation. Human agents (individuals, groups, organizations, communities, and other collectivities) produce, carry, and reform these systems of social rules, but this frequently takes place in ways they neither intend nor expect. ${ }^{3}$

On the macro-level of culture and institutional arrangements, we speak of established rule system complexes or rule regimes such as the language, cultural codes and forms, shared paradigms, norms and "rules of the game". ${ }^{4}$ On the actor level these translate into roles, particular norms, strategies, action paradigms, and social grammars (for example, procedures of order, turn-taking and voting in committees and democratic bodies). 5 Social grammars of action are associated with culturally defined institutional domains and roles, indicating particular ways of thinking, judging, and acting. For instance, in the case of gift giving or reciprocity in defined social relationships, actors display their social and cultural competence in knowing when and to whom a gift should be given or not, how much it should be worth, or, if one should fail to give it or if it lies under the appropriate value, what excuses, defenses and justifications might be acceptable. Rules and rule systems serve three (at least) basic functions/uses in all social life: (1) coordination/direction of social action and interaction; (2) understanding/simulation of what is going on or will go on in the future; and (3) referents in giving and asking for accounts, generating normative discourses, for instance of praise and of critique. ${ }^{6}$

The rules making up rules regimes consists of three qualitatively different kinds of rules: descriptive or declarative rules describing or defining reality, action or directive/regulative rules, and evaluative rules defining what is worth-while, good, valuable (or their opposites, "bads").

One of the contributions of rule system theory has been in conceptualizing universal interaction grammars (Burns and Flam 1987). Such grammars are complexes of rules applying to social action and interaction of individuals, groups, and organizations. These grammars consist of a finite set of rule types or categories that are identified in the following section. ${ }^{7}$

3 Social rule systems play a key role on all levels of human interaction (Burns et al. 1985; Burns and Flam 1987; Burns and Hall 2012; Giddens 1984; Goffman 1961, 1974; Harre 1979; Harre and Secord 1972; Lotman 1975; Posner 1989; among others), producing potential constraints on action possibilities but also generating opportunities for social actors to behave in ways that would otherwise be impossible, for instance, to coordinate with others, to mobilize and to gain systematic access to strategic resources, to command and allocate substantial human and physical resources, and to solve complex social problems by organizing collective actions.

4 Lotman (1975) and Posner (1989) offer valuable semiotic perspectives with important (not yet analyzed on our part) parallels.

5 There are not only role grammars but semantics and pragmatics, hence processes of meaning, interpretation, and adaptation associated with rule application and implementation.

6 Zelizer (2012) points out the importance of account-giving (as part of any established relationship); she refers to how people "repair" relations by justifying or explaining their actions which have caused damage or problems: "someone tells a story to show that the damage was inadvertent or unavoidable— "accidental"—and, therefore, despite appearances, does not reflect badly on the relationship between the actors. "Why" or "what were you thinking".

7 The determination of the universal rule categories for groups, diverse social organizations, and institutions was based on: (1) language categories that are reflected in "questions" and definitions/descriptions of socially regulated interaction situations: who, what, for what, how, where, when (Burns et al. 1985; Burns and Flam 1987); (2) interaction descriptions and analysis (of contextualized games, C-games) (Burns and Gomolinska 2000a; Burns and Roszkowska 2005, 2007, 2008); (3) comparative institutional analysis (Burns and Flam 1987). 


\subsubsection{Universal Interaction Grammars 8}

We have identified and applied universal rule grammars-in a comparative perspective- to human interaction and games as well as diverse institutions and institutional arrangements: bureaucracies, judicial systems, markets, democratic associations, etc. ${ }^{9}$

The conceptualization of universal interaction grammars enables us to systematically investigate and analyze group and organizational structures, interaction situations and performances, which rule regimes socially defined and regulated—and to do this comparatively-as one would compare the grammars of different languages. This is done in Burns and Flam (1987) in terms of defining social relationships and interaction patterns of diverse institutions. ${ }^{10}$

In the model of group and organizational rule regimes, ten (10) categories of rules are identified (see Tables 1-3) concerning group agency conditions, social structure, interaction, material conditions, and time and space: (A) Four categories concern agency relating to: Identity (I), Group membership (II), Share values, ideals, and goals (III), and Shared knowledge and beliefs (IV); (B) Group social relations and structure (category V); (C) Group action and interaction orders/patterning (VI, VII, VIII); (D) Material and resource conditions of group action and interaction (IX); and (E) Rules relating to group times and space conditions for group meetings and interactions. ${ }^{11}$

Table 1. Key Types of Rule Categories Specifying Group Conditions, Structures, and Processes. ${ }^{12}$

\begin{tabular}{|c|c|}
\hline Rule Types & Definitions \\
\hline Type I & Identity rules_-"Who are we?" "What symbolizes or defines us?" \\
\hline Type II & $\begin{array}{l}\text { Membership, Involvement, and Recruitment Rules-“Who belongs, who doesn't?" “What characterizes } \\
\text { members?" "How are they recruited?" }\end{array}$ \\
\hline Type III & Rules concerning shared value orientations and ideals_-"What does the group consider good and bad?" \\
\hline Type IV & $\begin{array}{l}\text { Rules concerning shared beliefs and models- "What do we know and believe about ourselves, our } \\
\text { group behavior, and our environment". }\end{array}$ \\
\hline Type V & $\begin{array}{l}\text { Social relational, group structuring, and governance rules. "How do we relate to one another, what is } \\
\text { our social structure?" "What are the authority and status differences characterizing the group?" "How } \\
\text { do we interact and reciprocate with one another and with the leadership?" "What are the rules of } \\
\text { internal governance and regulation?" }\end{array}$ \\
\hline Type VI & $\begin{array}{l}\text { Rules for dealing with environmental factors and agents ("external governance"). "How do we cope } \\
\text { with, make gains in the environment, dominate, or avoid environment threats?" }\end{array}$ \\
\hline Type VII & $\begin{array}{l}\text { Group production and activity rules. "What are our characteristic activities, practices, production } \\
\text { programs, ceremonies and rituals?" "How do we coordinate activities and make collective decisions?" }\end{array}$ \\
\hline Type VIII & $\begin{array}{l}\text { Rules and procedures for changing the rule regime, or for changing core group conditions and } \\
\text { mechanisms. "How do we (or should we) go about changing group structures and processes, our goals, } \\
\text { or our practices?" }\end{array}$ \\
\hline Type IX & $\begin{array}{l}\text { Technology and resource rules. "What are appropriate technologies and materials we should use in our } \\
\text { activities (and possibly those that are excluded)?" }\end{array}$ \\
\hline Type X & Time and Place Rules_-“What are our appropriate places and times?” \\
\hline
\end{tabular}

8 The focus here is on relational and organizational grammars. There are other types of social grammars such as those of language and money (Burns and DeVille 2007).

9 Although the focus of the research is on modern social organizations, the theory is applicable to families, clans, communities, etc. The theoretical and empirical research clearly demonstrated that there is no scale problem.

10 In the sociological game theory work of Burns and Gomolinska (2000a, 2000b), Burns, Gomolinska, and Meeker (Burns et al. 2001), and Burns and Roszkowska $(2005,2007,2008)$, games and established interaction settings are characterized and distinguished in terms of their particular grammars-grammars which allow one to predict the interaction patterns and equilibria of interaction settings and games.

11 Rules and rule regimes need not be explicit buy may be tacit, or partially tacit. At the same time, group members and outsiders may have misconceptions about the rules and their application. Thus, group members may deceive themselves and others about what rules they are applying and what they mean in practice, deception may be institutionalized in the form of ready-made discourses defining or explain a regime as just or efficient or optimal-for example, a market regime - when it is not. Members as well as outsiders may see what they have been led to see and understand. 
This regime is the basis of a cognitive-normative framework defining among other things group identity, its purposes, structural architecture, role relations including status and authority relations, groups divisions, procedures, characteristic activities, and patterns of interaction and production/outputs. ${ }^{13}$ The regime may be understood as consisting of a collective codebook, cultural tools and social organizational principles. There is an architecture of any rule regime, the cognitivenormative basis of the formation and functioning any group or organization (see Appendix A for illustrations).

Rules that are part of a group's rule regime are to a greater or lesser extent "known" to group members (some or many tacitly known); they are normally useable/implementable or applicable (provided requisite technologies and resources are available to the actor(s); and are considered functional or appropriate (or legitimate, as rules in an established regime). A group's regime provides the cognitive-normative basis of members to coordinate with one another, to collaborate and exchange in particular ways; to understand what is going on in the group, to simulate groups interactions and developments, and to refer to in giving and asking for accounts and in making normative judgments, criticisms as well as eulogies.

The theory does not require that the participants in interaction are in agreement with the rule regime (or any of its sub complexes). Group actors in diverse roles are expected to perform according to different grammars, but they may disagree and struggle over the appropriate grammars, the contents of particular categories of rules, or even details of a particular rule. As stressed in Burns and Flam (1987) (also see Burns and Hall 2012), there is at one time or another a "politics" (or potential politics) to social rules, those rules that are supposed to apply generally as well as the rules associated with particular roles, role relationships, production functions, and governance activities.

The ten universal rule categories presented here may not be fully specified in all interaction situations. Typically, the process of "institutionalizing" a group or a complex of relationships may entail overtime a piecemeal specification of the rules in the different categories. Long establishedinstitutionalized-groups and their relationships usually have rules specified in all the categories. However, this is an empirical question. ${ }^{14}$ Also, disruptions may occur as a result of political, economic, technological, or other social changes. Rules in particular categories that were taken for granted earlier may no longer be accepted or applied. Relationships which were hierarchical (with rule specifications appropriate to such relationships) are transformed into egalitarian relationships. Or the values and norms considered appropriate for particular relationships (whether in a family, religious community, work organization, political association) are transformed, shift, or are prioritized in radically different ways. ${ }^{15}$

12 In Appendix A, we present in more detail these universal rule types/categories (10) that make up a group or organizational rule regime.

13 This is not some "laundry list", hence our emphasis on the structure or architecture of rule regimes (Carson et al. 2009). The specification and analysis of rule complexes making up architectures goes back almost 40 years and was the basis of a reconceptualization of the theory of games and human interaction, a sociological theory of games (Burns 1990; Baumgartner et al. 2014; Burns and Gomolinska 2000a; Burns et al. 2001), and Burns and Roszkowska (2005, 2007, 2008; among other articles).

14 A rule regime does not necessarily consist of formal, explicit rules. It may be an implicit regime, which members of a group do not reflect upon (unless or until there is a crisis or performance failings, a "failed group experience"). The degrees of completeness as well as institutionalization of the regime are variables (see Footnote 4).

15 Shifts in the rules of public policy paradigms governing areas of policy and regulation are investigated and identified in Carson et al. (2009); the shifts concern values and goals, agents considered responsible, expertise, appropriate means, among other key rule changes. 


\subsection{Social Science Game Theory in a Nutshell (SGT) ${ }^{16}$}

In SGT games consist of (1) participating, mutually aware agents whose actions are interdependent; (2) rule regimes (cultural and institutional conditions and forms); and (3) resources (technologies, material conditions). Most games are embedded in rule systems making up social institutions and cultural foundations (Burns and Flam 1987).

(1) SGT theory is developed and applied to multi-agent interaction situations where there are interdependencies among two or more of the agents (as in classical game theory).

(2) A SGT game consists of a set of actors whose actions and action outcomes are interdependent; they interact in complex social and psychological contexts, subject to particular rule regimes (institutions, cultural formations (see Figure 1)) as well as material and technological constraints. Games are socially embedded-normative, relational, and institutional contexts are identified and taken into account in their influence on interaction conditions and perceptions, judgments, and actions of the participating actors.

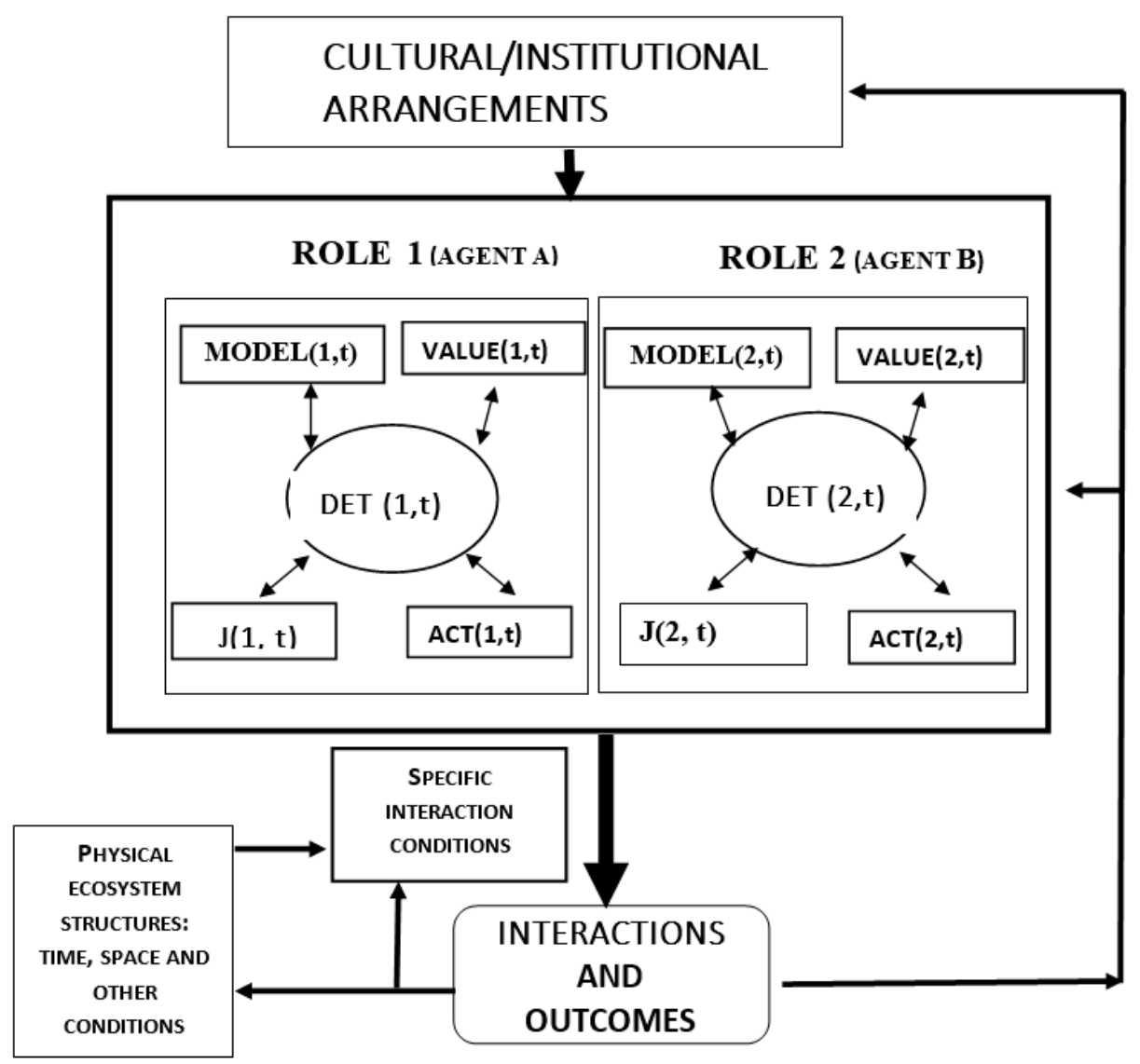

Figure 1. Two Role Model of Interaction Embedded in Cultural-Institutional and Natural Contexts.

16 SGT involves the extension and generalization of classical game theory through the formulation of the mathematical theory of rules and rule systems and a systematic grounding in contemporary social sciences (the classical theory is a special case of the more general SGT) (Burns et al. 2001, 2005, 2017; Burns and Gomolinska 1998, 2000a, 2000b; Burns and Roszkowska 2005, 2006 , 2007). Sociological concepts such as norm, value, belief, role, social relationship, and institution as well as classical game theory concepts can be defined in a uniform way in SGT in terms of rules, rule complexes, and rule systems (which in formalized SGT are also defined as mathematically objects). These tools enable one to model social interaction taking into account economic, social psychological, and cultural aspects as well as considering games with incomplete, imprecise or even false information. This approach has been developed by Tom Baumgartner, Walter Buckley, Tom R. Burns, Philippe DeVille, Anna Gomolinska, David Meeker, and Ewa Roszkowska, among others. 
Interaction and group behavior, its outputs (and consequences) are patterned in large part through actors performing their roles and adhering to norms; at the same time, they may make strategic choices, take strategic actions to better achieve a goal or to realize a role or norm (games are open).

(3) SGT provides a cultural/institutional basis for the conceptualization and analysis of games in their social context, showing precisely the ways in which social norms and rule complexes of social relationships, values, institutions, and social relationships come into play in shaping and regulating game agents and their interactions.

(4) The SGT approach to game theorizing rejects assumptions of super-rationality and maximization of one-dimensional utility. Instead, it stresses human choice and action based on social rule systems-in many of not most instances implementing norms, roles, and institutional arrangements. ${ }^{17}$ Typically, some or many properties of interactions and outcomes are unknown (unanticipated and unintended outcomes of actions and interactions are an inherent part of the SGT conceptualization).

(5) SGT distinguishes between open and closed games. The rule regime or structure of a closed game is fixed. In open games, actors have the capacity to structure, restructure, and transform game components such as the role components or the general "rules of the game". Even external agents ("third parties") may have the power ("meta-power") to structure and transform games (hence, "the prisoners' dilemma game has been analysed in SGT as a three-person game"). ${ }^{18}$ Each player has one or more roles in the game; in her role an actor has a set of given strategies in closed games; in open games, she may develop strategies as the interactions among players evolve. In general, actors may to a greater or lesser extent change the strategies or option as well as the rules, roles, norms, players, context, etc.

(6) Rules governing Communicative actions. Communication conditions and forms are specified by the rules defining action opportunities and repertoires in any given game situation.

In whatever ways the norms and institutional arrangements are established and maintained, the sociological approaches provide a language and analytic tools to describe and analyze a wide variety of communication situations distinguishable by their particular group norms and institutional arrangements. ${ }^{19}$

(7) Extraordinary Social Knowledge. While SGT readily and systematically incorporates the principle that human actors have bounded factual knowledge and computational capability, it emphasizes their extraordinary socio-cultural and institutional knowledge and competences: in particular, their knowledge of diverse cultural forms and institutions such as in the context of family, market, government, business or work organization, hospitals, and educational systems, among others, knowledge which they bring to bear in framing and engaging in their social relationships and game interactions.

(8) Action Determination Array. The action determination array (DET[G,S, i]) consists of a finite set of algorithms for determining action (including response(s) in relation to the actions of others). Each modality has one or more algorithms that generate actions or make selections of action, for instance, algorithms for implementing or "following" a ritual, norm, role, role relation (together

17 SGT, in addition to its empirical grounding, provides the conceptual and mathematical foundations of rules and rule systems (Burns and Gomolinska 2000a; Burns and Roszkowska 2005, 2007)—ironically, classical theory defined games as systems of rules but never developed a conceptualization and mathematics of rules and rule systems.

18 Open games - with their opportunities for creativity and innovation-are obviously less predictable in their interaction and outcome patterns than closed games with fixed action repertoires and given outcomes. Even in many closed games the actors vary to a greater or lesser extent in their interpretations, adjustments, and enactments of the norms and algorithms associated with their roles, introducing variation in the situation (for instance, in superordinate-subordinate interactions, in peer group interactions, or in gender interactions).

19 SGT readily incorporates the possibilities of "communication among players" and the making of binding agreements-which are the bases of what are referred to in classical game theory as "cooperative games". But there is much greater variety and complexity in human interaction-in particular, communication-than the distinction between cooperative and non-cooperative games would suggest. 
with others), or an institutional arrangement; judgment algorithms for choosing or shaping action alternative(s). ${ }^{20}$

The concept of action determination refers to the basis on which actors perform and action, make choices among given alternative actions, or construct their actions. Games in the SGT perspective range from rule prescribed social actions and interactions to actions and interactions that entail various degree of choice. Three main classes of ideal-type algorithms of action determination are distinguished: algorithms for implementing a rule or rule complex, algorithms or procedures for choosing among alternatives, and algorithms and strategies for constructing or creating an action.

A. DET-I: Following or implementing an appropriate or prescribed norm, role, institutional arrangement (with multiple participants), that is a rule complex or algorithm is implemented. Social actions and interactions are routinized, ritualistic; performance or enactment is matched with a specified norm or procedure in a given interaction situation $S$ and game $G$, with actors $i, j, k \ldots$ in their role and role relationships. If two actors, $\mathrm{A}$ and $\mathrm{B}$, in a 2-person game have established paired rule complexes to implement, the interaction is routine/predictable. Even if content changes-within some limits-the interaction is produced in routine and predictable ways.

The procedures for following or implementing a rule or rule complex: There is activation of the rule or rule complex and the performer compares and "matches" the experience or perception of the act with the qualities or details specified by the rule or rule complex. (Whole production systems operate more or less in this way: organ transplantation systems (Machado 1998); hydro-power planning and decision-making frameworks (Burns and Flam 1987)).

B. DET-II: This type of algorithm applies to assessing and choosing among alternatives. An agent is faced with a "crossroad," alternative actions, multiple possible strategies, or distinct modalities of action determination

For instance, there is choice between two or more action alternatives; or a choice is made between an action of normative realization or action promising instrumental gain. Or choosing between an extreme emotional expression (emotional modality) and an instrumental one (limiting emotional expression for the purpose of gaining from another agent such as an employer). Procedures or algorithms to make individual and/or collective choices. However, on what basis? Such procedures or algorithms chooses the alternative most similar to an applicable norm or value; that is, the various alternatives are compared to the relevant norm or value, and their degree of similarity is assessed. The actors choose the most similar alternative- or the one that is ranked highest in terms of similarity.

C. DET-III: This modality entails finding or constructing one or more action alternatives in an initial phase. A second phase entails the decision to approve or accept the constructed or derived actions. In case of alternative options, the agent(s) makes an assessment and choice among the alternatives, that is uses a DET-II modality.

Because of a blockage of an established activity, or its failure to do what it is supposed to do, the agent is driven to construct or generate one or more action alternatives. Similarly, agents are engaged in creative or innovative efforts.

Note that the "determinations" DET-II and DET-III are finalized through DET-I modalities of rule following or enactment. Note also that the conception of action determination replaces the more limited notion of "decision-making" and entails, as outlined above, either "following or enacting a rule", selecting or choosing among rules, or constructing or adopting new rules.

(9) Game transformation. Game re-structuring and transformation is conceptualized in SGT through constructive actions of game agents and/or external agents. It is based on the innovative or creative capabilities of game participants; exogenous agents also engage in shaping and reshaping games. In such "open games", the players may restructure and transform the game, its norms, its roles,

20 Emotional judgment algorithms result in particular actions in "emotionally charged situations". Expressive or communication action entails enacting a script in a defined or appropriate situation. 
and role relationships and, thereby, the conditions of further actions and interactions. SGT agents are, in part, creative, moral and ritualistic, as well as transformative beings, in part strategic (that is, "rational" but with limited ("bounded") rationality).

(10) Normative equilibria. In SGT, games and interaction processes result in the production and manipulation of institutions, social relationships, roles, norms-and these serve, in general, as equilibria, normative equilibria (right actions, distributive justice, etc.), which is the basis of much social regulation and order.

SGT encompasses strategic behavior, on the one hand, and routine and institutionalized activity as well as ritualistic and symbolic behavior, on the other hand. ${ }^{21}$ Of course, some interactions approach the pure or ideal ritual or symbolic; others approach the pure strategic. In addition, of course, as Goffman $(1959,1969)$ and also Zelizer (2012) stress, people are capable of combining ritual and strategic modalities (in some cases, possibly having to "work hard" at it or drawing on rich culturally established traditions to produce complex patterns).

In a sociological perspective, actors' attention may be less to outcomes (as in classical game theory) than to situationally appropriate symbols and rituals. Also, actors attend to the production of a "self", an "image", a "self-presentation", or a group, community, or national "identity" (Goffman 1959). For instance, actors work at producing or realizing the symbols and properties of gender (Zelizer 2012) as well as the production or realization of a particular body form, male or female, in many instances, as "attractive" as possible-with aesthetic goals in the interaction situation.

SGT encompasses theoretically in a seamless manner collaborative interactions, on the one hand, and conflict situations, on the other hand. In collaboration and other forms of cooperation, the participants share information, avoid actions that would contradict or undermine the collaborative relationship. ${ }^{22}$ In a hostile relationship (which is more than simply a "zero-sum" situation), the participants are likely to choose actions to harm one another; even at great cost to oneself or the loss of opportunities for mutual gains; in extreme cases, they reject gainful collaborative opportunities, and seek situations or to produce situations with zero-sum properties. ${ }^{23}$ When it comes to questions of the use and abuse of information, the differences are clear-cut. Collaborators are predisposed to share information-except for information about themselves or their behavior, which would undermine their mutual good-will and collaborative relation-facilitating their collaboration on relevant tasks and production processes. Although positive to one another, they may engage in "benign" forms of deception, for instance, not revealing or denying instances of hostility, deception, or performance failure. In contrast, actors having hostile relationships not only withhold information that would be helpful to the other, for instance, in avoiding harmful or risky actions. Lying, deception, and cheating are consistent with the character of the relationship (but would be incompatible with a cooperative or collaborative relationship).

21 At the same time, ASD's theory of social action and interaction rejects the conception of an abstract, super-rational actor underlying rational choice, economics and game theories. Or more precisely, it treats games be-ween "rational egoists" as only a special, limiting case. ASD assumes, instead, that human agency-choice, action and interaction-are socially embedded (Granovetter 1985). The focus is on socially constituted agents, their roles, role relationships, cultural and institutional frames that orient and constrain them in their interactions. The theory identifies the organizing principles, social relationships and rules that actors apply to specified interaction situations and that make for particular action and "interaction logics" (Karpik 1981; Wittrock 1986) or socially conditioned rationalities (Burns and Flam 1987). In other words, rationality is a function of the rules, rather than rules being a simple expression of rationality (see Mirowski 1986; 1981, p. 604).

22 There are many institutionalized forms of cooperation: from classical game theory 'minimalist' forms where the actors can communicate and make binding agreements to cooperative forms entailing sharing group identity, powerful solidarity, and compelling normative framework defining correct (and, of course, incorrect) relations of cooperation.

23 As in the case of cooperative and collaborative relations, there are multiple forms of "conflict" relations: from classical game theory's "zero-sum" interaction situation (defined in terms of payoff structure) to relationships with mixed orientation among the actors (positive and negative feelings) as well as to relationships strong emotional hostility, even hatred. 
Established relations are, in a SGT perspective, maintained and reproduced in interaction patterns and equilibria. Social relationships among participants in a group or organization influence, of course, the way they act vis-à-vis one another and the outcomes of their interaction.

- Established relationships even influence actors' selection of interaction situations, or their avoidance of certain situations, or their adjusting or transforming certain situations so that they are compatible with-or match-the relationships and normative order. For example, a group of research colleagues often restructure a meeting place to be more like a seminar for peers rather than a lecture hall (unless, of course, a lecture is planned).

- When a negative interaction situation cannot be controlled or restricted by the participants, they try to "act under the circumstances" in ways appropriate to their cooperative relationships. Unless one or more decide to give up on a relationship, and bracket it. In other words, they may play the "situational" game as it should be played and bracket their friendship or kinship while the game-with its rules diverging from friendship or kinship relations-is being played.

- $\quad$ Earlier (Burns and Roszkowska 2005, 2006), we modeled how the norms of asymmetrical relationships, such as status relationships based on gender, education, ethnicity, professional association (including military, hospital and educational systems), indicate appropriate and equilibrium interaction behavior and outcomes, namely asymmetrical ones. Zelizer (2012) speaks in terms of the actors "conducting relational work" in order to select or produce interactions and outcomes that are compatible with the relationship - they try to find and reproduce patterns that confirm their sense of what the relationship is all about and try to maintain these patterns or practices. In general, actors try to match their interactions, for instance, economic transactions, with the "meaning of the particular relation". "Relational work consists in creating viable matches among those meaningful relations, transactions, and media". She continues, "In Purchase of Intimacy (2007) I note that relational work becomes especially consequential when relations resemble others that have significantly different consequences for the parties. In such cases, people make extra efforts to distinguish the relations and mark their boundaries: To the extent that two relations are easily confused, weighty in their consequences for participants, and/or significantly different in their implications for third parties, participants and third parties devote exceptional effort to marking what the relationship is and is not; distinctions among birth children, adopted children, foster children, and children taken in for day care, for instance, come to matter greatly for adult-child relations, not to mention relations to the children's other kin".

Notice the importance of the coherence of a group rule configuration at the same time that it is distinguished from those of other groups. The performances and practices that are generated are expected to reflect the distinctions among groups-otherwise there would be confusion and disorder (see later discussion).

Establishing new relations or changing established relations. Such a mechanism has been specified and analyzed in SGT investigations as well as conceptualized in terms of meta-processes, the exercise of meta-power and relational control (Burns et al. 1985; Burns and Hall 2012). ${ }^{24}$

In the perspective of SGT social relationships and institutional arrangements-the social rules, roles, and role relationships of groups, formal organizations, communities, networks, etc.- - are continually maintained and reproduced as well as modified through group interaction and negotiation as well as social structural and ecological selectivity. ${ }^{25}$ The modifications are substantial in some

24 Zelizer (2012) (and also C. Tilly) refer to this type of phenomenon in terms of creating, maintaining, transforming, or terminating (interpersonal) relations. Zelizer identifies four kinds of such relational or meta-power work: (A) creation of new relations; (B) maintaining existing relations (among other things, "affirming" existing relations); (C) negotiating shared definitions of relations (including situational definitions); (D) correcting or regulating immediate deviations; (E) repairing damaged relations; $(\mathrm{F})$ restructuring or transforming relations.

25 Social rule system theory (Burns 2008; Burns et al. 1985, Burns and Flam 1987; Flam and Carson 2008) was formulated and developed in the 1980s making a modest contribution to the new institutionalism (Powell and DiMaggio 1991). 
instances, entailing shifts between, or transformations of, core organizing principles and particular normative rules and systems of rules (e.g., family and gender relations, the relations of the rational-legal bureaucracy, democratic forms, and market arrangements) in modem societies. Various social agents-actively and creatively engaging in such processes-determine to a greater or lesser extent which rule regime or social order is to govern a complex of relationships in a particular sphere of activity or social setting (Burns and Flam 1987). Agents with relevant commitments and vested interests struggle to maintain established systems, or to limit changes in them. Others act openly or covertly to modify, avoid or transform the systems.

At the core of the SGT framework are concepts such as norms, values and judgment processes, enabling one to describe and analyze actors' orientations about right and wrong and good and bad in their particular interaction situations. ${ }^{26}$

The SGT approach to reforming game theory-or more precisely, formulating an alternativeemphasizes, as would be expected, the importance of taking into account and analyzing such factors as the social context, the particular social relationships, roles, and norms of the 'actors'.These factors contribute to defining many if not most of the "rules of the game". In such a perspective, games or interaction situations are "socially contextualized or embedded" (Burns et al. 1985; Granovetter 1985). ${ }^{27}$

In general, SGT considers a rich variety of relationships and their interaction patterns: friendship, enmity, neutral relationships, superior-subordinate relationships institutionalized in groups and organizations such as those involving leadership. Classical closed games in different socio-cultural contexts results in diverse interaction patterns and outcomes as a function of the norms of particular social relationships-and they are also common-sensical, since most know what to do or what to expect in these different relationships. In groups and organizations with well-defined solidary role relationships, participants in "zero-sum" or "PD" type situations tend to act cooperatively (and predictably) rejecting the "rational" patterns of interactions and outcomes. For instances, subordinates make sacrifices for their superiors so that interaction patterns and outcomes are congruent with their defined role relationship. If there are no options congruent with their role relationship, they are likely to try to restructure or transform the situation into one with congruent patterns-or to avoid such situations altogether.

In open game situations, actors have opportunities to individually and/or collectively develop new strategies or action opportunities. Actors in solidary relationships will tend to collaborate in solving problems-in-common. Participants in enmity relations would not tend to collaborate and work out.

Whyte in his Street Corner Society (REF) reports on ways that in a street corner gang lower status members were psychologically and socially driven to lose at bowling when playing with their higher status members-regardless of being in some cases unmistakably more capable. These patterns contributed to safeguarding the group's social structure and ultimately the group's very existence by acting in ways to maintain social relationships and the social order. Established status ritual and discourses typically play an important role in such social structuring work ("relational control") (Burns and Hall 2012).

Additionally, social actors involved in a variety of interactions may purposefully avoid situations involving conflicts such as zero-sum situations because those outcomes could entail unacceptable results for

26 In contrast, rational choice and game theories provide little or no analytical capability to address such matters, in large part because they lack conceptual tools to deal with such universal matters as social values, norms, social structures, institutional and cultural formations, value dilemmas and conflicts. The utilitarian foundation is simply all too constraining.

27 Some like Peterson (1994), but also Swedberg (2001), claim that Game Theory has proved only sporadically useful to sociologists, while Abell (2000) argues it ought to have a greater influence in sociology, and Edling (2002) claims that it has mostly affected mathematical sociology, but that its core-yet most basic principle "... that social actors interact, and are affected by game outcomes, albeit in different ways, by that interaction" is basic sociology. While Swedberg (2001) long ago pondered the possibility of developing a distinctively sociological game theory approach without acknowledging earlier initiatives such as IGT and SGT, he mostly saw and partially articulated the idea of game theory in order to theorize "counterfactuals". But, of course, given its empirical failings, it would be a poor tool for generating 'counterfactuals'. 
self and others; this is particularly the case of actors with solidarity relationships such as, for example, friendship, as well as for those involving status or authority hierarchies as in the example above from Street Corner Society.

Informal gender interactions are typically highly codified, and do not involve a maximization of outcomes, but instead entail the use of cultural scripts and rituals to maintain a particular social relationship or order (often underlying the preservation of hegemony by one type of actor or group over another). ${ }^{28}$

These cases help us see how much complexity is involved in many forms of interaction which classical game theory lacks the language, the conceptual tools to effectively describe and analyze. ${ }^{29}$

The following sections elaborate GT and SGT conceptualizations in applications to the description and systematic differentiation of groups and organizations and their comparative analyses.

\section{Elaboration of Group and Game Theories and Their Interrelationships}

\subsection{Group Differentiation According to Group Rule Configurations}

For any given group in its material and social context, the different content rules in the universal rule categories make up stable sub-complexes-subcultures-linking, for instance, particular value/goal rules relate to involvement/recruitment rules and group identity rules as well as production and resource rules. In other words, a given group fills up the contents of the universal rule categories in its own particular ways - which has an identifiable logic. ${ }^{30}$ That is, the various content rules relate to one another systemically for a given collective.

One can envision a matrix of rule interdependencies with compatibility constraints among the rules. We refer to such interrelationships as group rule configurations (which for an established, enduring group are often social equilibria (Burns and Roszkowska 2006)). ${ }^{31}$ An important class of rule configurations entail linkages among group identity rules (category I), group purpose and value orientation rules (category III), involvement/recruitment rules for involving and socializing committed and capable actors (category II), an appropriate set of relations and roles for the tasks of accomplishing group productions/performances (V), appropriate production programs or functions for realizing or accomplishing group goals/values (VI), appropriate resources (materials and technologies) (IX) for the production functions, and appropriate/legitimate time and places to conduct these group activities (X). Table 2 presents one illustration of a rule configuration, in this case, the $9 / 11$ terrorist group (Dermott 2005; Kean 2014; see also later).

28 Concerning gender, women use makeup, utilize "sexy" or "feminine" clothes (especially, lipstick and other face makeup, bras, high-heel shoes, dresses) to express or to emphasize their identity. At the same time that they are constructing their female identities, men may misinterpret this behavior as an 'invitation', a "come-on", revealing a "readiness for sex". It is not surprising that young girls may hardly understand the full meaning of what they are doing as they try to become "women".

29 Examples of complex games comes from Ugo Corte's ethnographic work on the social world of surfing and big wave surfing in particular. Surfers' scarce resources are waves. Surfers compete with one another, and also collaborate, to catch as many of the best waves during a specific day without letting any major waves go by un-ridden and thus wasted. Surfing is a subtle and complex social game-with strategic as well as rule following and ritual behavior-in a natural context of waves to be used in performance, but in some instances entailing danger and risk part of it derived from the activity itself, while the rest having to do with the releant complex of social norms.

30 The methodological approach linking universal rule categories to the particular rule contents in these categories may have parallel's with Simmel's formalism where universal grammars with respect to which actors behave in ways characterized by the particularity of their contexts (Gross 2009).

31 The linkages may vary in the tightness (or looseness) of their couplings. In a loosely coupled configuration, a disturbance or shift in the rules of one category may not readily spread to the rules of other categories. On the other hand, in a tightly coupled configuration, a disturbance in the rules of one category tend to destabilize others. 
Table 2. Illustration of a Particular Group Rule Configuration.

\begin{tabular}{|c|c|}
\hline Rule Type & $\begin{array}{l}\text { Terrorist Group Rule Configuration (For instance, the 9/11 Group; } \\
\text { see Dermott 2005; Kean 2014; also Table 3) }\end{array}$ \\
\hline Defining Identity (I) & $\begin{array}{l}\text { Group name, possibly logo. Identity associated with the terrorist goals and } \\
\text { possibly with the particular methods or strategies used. "Negative" dress code to } \\
\text { conceal identity when operating clandestinely. }\end{array}$ \\
\hline $\begin{array}{l}\text { Recruitment of Membership } \\
\text { Participation/Involvement (II) }\end{array}$ & $\begin{array}{l}\text { Recruitment and training of capable and committed members, willing and able to } \\
\text { carry out terror acts. Covert participation. Dress code and code of silence to } \\
\text { conceal identity. Strict obedience to leaders and group rules. }\end{array}$ \\
\hline $\begin{array}{l}\text { Shared Value(s), Purposes, } \\
\text { Goals (III) }\end{array}$ & $\begin{array}{l}\text { Orientation to carry out deadly attacks against designated categories of targets; } \\
\text { accomplish destabilizing actions, create terror. }\end{array}$ \\
\hline $\begin{array}{l}\text { Shared beliefs/Model of reality } \\
\text { rules (IV) }\end{array}$ & $\begin{array}{l}\text { The world is divided between Muslim believers and non-Muslim believers; } \\
\text { the latter are enemies, polluters that will undermine and destroy Islam. } \\
\text { Even some "quasi" Muslim groups are a threat to a holy Islam. }\end{array}$ \\
\hline $\begin{array}{l}\text { Group Relations of Reciprocity } \\
\text { and Leadership (V) }\end{array}$ & $\begin{array}{l}\text { Strict hierarchy, maintenance of strict separation among members } \\
\text { (thus, independent cells). }\end{array}$ \\
\hline $\begin{array}{l}\text { Production and Output } \\
\text { Functions (group protection } \\
\text { and maintenance; hostile and } \\
\text { destructive actions) (VI) }\end{array}$ & $\begin{array}{l}\text { Deployment and use of terrorist weapons; actions to conceal identity and } \\
\text { operations. Procurement of weapons, safe houses, financing; Appealing to } \\
\text { potential recruits. }\end{array}$ \\
\hline $\begin{array}{l}\text { Relations with the } \\
\text { Environment (VII) }\end{array}$ & $\begin{array}{l}\text { Identification of enemies and targets; concealment, avoiding detection and } \\
\text { monitoring. Identification of potential recruits. }\end{array}$ \\
\hline $\begin{array}{l}\text { Rules and Procedures for } \\
\text { Changing the Rule Regime, } \\
\text { Particular Rules }\end{array}$ & $\begin{array}{l}\text { Ways the group changes rules, roles, and policies. Typically, part of an } \\
\text { authoritative hierarchy. }\end{array}$ \\
\hline $\begin{array}{l}\text { Group Resources (IX) } \\
\text { (materials and technologies) }\end{array}$ & $\begin{array}{l}\text { Weapons of destruction; safe houses. Sufficient funding to obtain weapons and } \\
\text { establish effective concealment; and to engage in the preparations such as } \\
\text { training and travel. }\end{array}$ \\
\hline $\begin{array}{l}\text { Times and Places for Group } \\
\text { Activities }(X)\end{array}$ & $24-7$ readiness, available safe group spaces, training camps. \\
\hline
\end{tabular}

In the following sub-section, we differentiate and compare selected groups according to their particular rules specified in the universal categories, that is, their group rule configuration.

\subsection{Group Rule Configurations and Differentiation among Groups}

Groups are distinguishable according to their value orientations and purpose(s) (spiritual, economic interests, artistic creation, coercive and/or sadistic engagements), social structure (for instance, hierarchical, egalitarian, mixed), basis of group involvement and commitment (e.g., normative, affinity-attraction, remunerative, coercive), resource dependence, characteristic patterns of group behavior, and impact on the environment. Group research enables the systematic identification and specification of the major contents of universal rule categories.

The conceptualization of rule configuration is operationalized for a selection of several group systems in Table 3 characterizing diverse ideal types of groups. The cases are selected for their diversity and illustrate eight rule categories for each type of group (see Section 1.2.2 and Appendix A). ${ }^{33}$

32 The purposes are "legitimate" ones—and ideal types at that. But military as well as police purposes may be transformed (or degenerate) into counter-opposition and political repressive missions instead of "national defense" and ordinary "law enforcement functions", respectively, substantially poisoning the institutions and impacting negatively on their societies, processes exemplified in many contemporary Latin American and African countries.

33 Interestingly, Perrow (1967) suggested a similar idea for the comparative analysis of organization, although he claimed to reject "systems theoretic" approaches (personal communication). He framed his model in terms of patterns of variables rather than patterns of rules. Of course, rule patterns are translated or implemented in patterns of performances/outputs and practices, therefore, readily expressable in terms of variables. His intuition was that an ideal type of organization would have 
We distinguish, on the one hand, self-organizing groups (e.g., gangs, some terrorist groups, friendship groups, and many recreational groups (as well as many research teams and business "partnerships"(Columns B and D (and possibly C))), from, on the other hand, higher order constructed or "legislated" groups (military units, business units, research institutes, administrative groups and organized units at workplaces), established and maintained by a more encompassing organization and leadership (Columns A, C, D, E, F). ${ }^{34}$ Groups including alliances, intergroup, and other similar entities may be formed through negotiation among agents.

The illustrations in Table 3 are fuzzy or rough ideal types, not crisp empirical cases (for SGT's use of concepts of fuzziness, see (Burns and Roszkowska 2001, 2004; Roszkowska and Burns 2010). ${ }^{35}$

\subsection{The Coherence of Group Rule Configurations}

As indicated above, a group rule configuration does not consist of randomly selected or ad hoc rules, but of rules having some minimum degree of linkage and coherence among them. The group rule configurations presented comparatively in Tables 2 and 3 exhibit a degree of coherence imposed by its members and/or by external agents constructing the group. ${ }^{36}$ Otherwise, people would not recognize and have stable expectations about the group ideal types; and they would not be able to distinguish identities among different groups due to contradictions and confusion in group properties; the recognition aspect is important in addition to a configuration's key role in actual group functioning. ${ }^{37}$ The coherence of a group rule configuration is essential to group social order: to its predictability, understandability, and controllability (through rule based controls) of behavior in the group. To varying degrees, groups try to establish and maintain rule coherency and stringency of implementation for purposes of constructing a predictable social order with reliability (at least for themselves and possibly for others where relevant). ${ }^{38}$

particular properties making up a configuration. And he rightfully suggested that this basis for comparative analysis and distinctions among types was more powerful than the typologies proposed by Talcott Parsons (functionalism) (Parsons 1951), Amitai Etzioni (the bases of organizational control) (Etzioni 1975), Peter Blau and Richard Scott (the dimension of who benefits or gains from organizations) (Blau and Scott 1962), etc.

34 As suggested earlier, any given configuration will have a history and evolutionary dynamic driven and shaped by internal as well as external forces.

35 In other words, in SGT perspective, the abstract group is an ideal type. Any empirical case can be located in a space between the ideal type and its counterpoints in practice, where distances are measured on multiple dimensions, although the notion of a "group" is a fuzzy concept-any empirical group is an approximation to an ideal type group. It can usually be distinctly differentiated from its negation or opposite, a collection of non-related actors neither oriented nor committed to any social organizational regime regulating members' behavior and group behavior as a whole.

36 Another rule configuration property would be the degree of coupling (tight vs. loose coupling) among rules: the extent to which the activation of one rule or rule complex/algorithm leads to the automatic activation of one or more connected rules or rule complexes/algorithms (articulated in the work of Perrow (1967)). Some rules have buffers between them, or agents making judgments whether or not to pass a signal on-such "loose coupling" may or may not occur through the intervention of human agents or may occur through design of the system. Perrow and others have used considerations such as "tight coupling" to assess the degree of vulnerability of financial systems or other socio-technical systems to go out of control and crash. Consideration of degree of tight coupling and degree of coherence leads to an insightful $2 \times 2$ table (other properties of rule systems may be taken into account and introduced into such analyses).

37 This conception of coherence can be related to what the neo-institutionalists refer to-mostly metaphorically-as "institutional logic" (or logics).

38 Notice that the need to coordinate participants and maintain social order is arguably a more decisive factor in general than technology in determining group social organization (Perrow 1967). 
Table 3. Illustrations of Group Rule Configurations.

\begin{tabular}{|c|c|c|c|c|c|c|}
\hline & $\begin{array}{l}\text { Business Unit (A) } \\
\text { (Illustration) }\end{array}$ & $\begin{array}{l}\text { R\&D Institute (B) } \\
\text { (Illustration) }\end{array}$ & $\begin{array}{l}\text { Recreational, e.g., a Club } \\
\text { (C) (Illustration) }\end{array}$ & $\begin{array}{l}\text { Professional Army Unit (D) } \\
\text { (Illustration) }\end{array}$ & $\begin{array}{l}\text { Terrorist Group } \\
\text { (Illustration) (E) }\end{array}$ & $\begin{array}{l}\text { Prison Institution (F) } \\
\text { (Illustration) }\end{array}$ \\
\hline Defining Identity (I) & $\begin{array}{l}\text { Trade name, logo; possibly } \\
\text { badges, dress code, even } \\
\text { uniforms. Likely a particular } \\
\text { location or building(s). } \\
\text { Identity also defined by the } \\
\text { goal orientation to economic } \\
\text { gain (which often trumps } \\
\text { other goals) (see category III) }\end{array}$ & $\begin{array}{l}\text { Institute name, possibly logo. } \\
\text { Minimal or no dress code. } \\
\text { Identity associated with the } \\
\text { research goals, typically in a } \\
\text { particular research area and } \\
\text { possibly with the methods or } \\
\text { equipment used. }\end{array}$ & $\begin{array}{l}\text { Group name (e.g., club } \\
\text { name), possibly with logo. } \\
\text { Minimal or no dress code. } \\
\text { Identity associated in part } \\
\text { with the particular group } \\
\text { activity and its location. }\end{array}$ & $\begin{array}{l}\text { Unit's name, logo or insignia } \\
\text { and markings of rank. } \\
\text { Particular military uniform } \\
\text { as dress code. Possibly a } \\
\text { particular location. Identity } \\
\text { in part defined by the goal } \\
\text { orientation and the means } \\
\text { used (military power) (see } \\
\text { rule categories (III) and (VI)) }\end{array}$ & $\begin{array}{l}\text { Group name, possibly } \\
\text { logo. Identity associated } \\
\text { with the terrorist ideology } \\
\text { and goals and possibly } \\
\text { with the particular } \\
\text { methods or strategies } \\
\text { used. "Negative" dress } \\
\text { code to conceal identity }\end{array}$ & $\begin{array}{l}\text { Prison name. Guards also } \\
\text { uniformed. Identity } \\
\text { associated with the purposes, } \\
\text { means, technologies, } \\
\text { characteristics of the prison } \\
\text { and its population. Prisoners } \\
\text { typically subject to a uniform } \\
\text { dress code. Thus, dual } \\
\text { social order }\end{array}$ \\
\hline Recruitment (II) & $\begin{array}{l}\text { Skill-based recruitment; } \\
\text { Search for persons and } \\
\text { groups sufficiently oriented } \\
\text { to and acceptant of } \\
\text { remuneration levels } \\
\text { provided as well as } \\
\text { performance demands }\end{array}$ & $\begin{array}{l}\text { Recruitment based on } \\
\text { expertise/merit, and/or } \\
\text { formal education/training of } \\
\text { individuals or groups in the } \\
\text { relevant field or domain of } \\
\text { the group. }\end{array}$ & $\begin{array}{l}\text { Affinity group of friends, } \\
\text { relatives or people with } \\
\text { common interest in the } \\
\text { recreation ("buffs") and } \\
\text { getting together. }\end{array}$ & $\begin{array}{l}\text { Formal recruitment and } \\
\text { training of able and willing } \\
\text { unit members to obey and } \\
\text { perform violent acts (based } \\
\text { on honor, payment } \\
\text { (mercenaries), conscription } \\
\text { (coerced involvement)) }\end{array}$ & $\begin{array}{l}\text { Recruitment and training } \\
\text { of capable and committed } \\
\text { members, willing and } \\
\text { able to carry out } \\
\text { terror acts }\end{array}$ & $\begin{array}{l}\text { Guards are recruited. Strictly } \\
\text { speaking, prisoners are not } \\
\text { "recruited". They have been } \\
\text { arrested and confined. Thus, } \\
\text { again a dual social order. }\end{array}$ \\
\hline $\begin{array}{l}\text { Membership and } \\
\text { Participation/ } \\
\text { Involvement (II) }\end{array}$ & $\begin{array}{l}\text { Contractual engagement. } \\
\text { Members are remunerated } \\
\text { and with careers and rewards } \\
\text { for high performance. } \\
\text { Sanctioning for disloyalty } \\
\text { and disobedience. }\end{array}$ & $\begin{array}{l}\text { Members are remunerated } \\
\text { and with careers. Informal, } \\
\text { relatively lax sanctioning for } \\
\text { breaking group norms and } \\
\text { values. Loyalty to the } \\
\text { knowledge production cause } \\
\text { and the professional code of } \\
\text { ethics-negative sanctioning } \\
\text { for deviance from these. }\end{array}$ & $\begin{array}{l}\text { Informal, relatively lax } \\
\text { sanctioning for breaking } \\
\text { group norms and values. } \\
\text { However, there are limits. }\end{array}$ & $\begin{array}{l}\text { Members are typically } \\
\text { remunerated and with } \\
\text { careers in modern armies. } \\
\text { Highly codified, harsh } \\
\text { punishment for breaking key } \\
\text { group rules, in particular } \\
\text { those concerning loyalty and } \\
\text { obedience to the leadership, } \\
\text { group norms, and its symbols }\end{array}$ & $\begin{array}{l}\text { Covert participation. } \\
\text { Dress code and code of } \\
\text { silence to conceal identity. } \\
\text { Strict obedience and } \\
\text { loyalty to leaders, group } \\
\text { rules, and symbols. }\end{array}$ & $\begin{array}{l}\text { Dual social order. Guards are } \\
\text { remunerated and with } \\
\text { careers-and are expected to } \\
\text { obey rules and exhibit loyalty } \\
\text { to the prison administration. } \\
\text { Prisoners are alienated and } \\
\text { generally oppositional. }\end{array}$ \\
\hline $\begin{array}{l}\text { Purposes/Values } \\
\text { (III) }{ }^{39}\end{array}$ & $\begin{array}{l}\text { Pursuit of money-making; } \\
\text { possibly also values of } \\
\text { making quality goods and } \\
\text { services, satisfying clients }\end{array}$ & $\begin{array}{l}\text { Produce new knowledge or } \\
\text { technology. Innovate/create } \\
\text { and experience "flow", } \\
\text { possibly also to achieve } \\
\text { symbolic power and } \\
\text { scientific prestige as well as } \\
\text { "gains in resources". }\end{array}$ & $\begin{array}{l}\text { Mutual pleasure, getting } \\
\text { together, "having fun" }\end{array}$ & $\begin{array}{l}\text { Defense/ Offense (external); } \\
\text { also, orientation to possibly } \\
\text { exercising control internal to } \\
\text { the society (coups) }\end{array}$ & $\begin{array}{l}\text { Orientation to carry out } \\
\text { deadly or intimidating } \\
\text { attacks against } \\
\text { designated categories of } \\
\text { targets; create terror, } \\
\text { accomplish } \\
\text { destabilizing actions. }\end{array}$ & $\begin{array}{l}\text { Maintain law and order. } \\
\text { Divided (and divisive } \\
\text { purposes) between guards } \\
\text { and prisoners. }\end{array}$ \\
\hline
\end{tabular}

39 The purposes are "legitimate" ones-and ideal types at that. But military as well as police purposes may be transformed (or degenerate) into counter-opposition and political repressive missions instead of "national defense" and ordinary law enforcement functions, respectively, substantially poisoning the institutions and impacting negatively on their societies, processes exemplified in many contemporary Latin American and African countries. 
Table 3. Cont

\begin{tabular}{|c|c|c|c|c|c|c|}
\hline & $\begin{array}{l}\text { Business Unit (A) } \\
\text { (Illustration) }\end{array}$ & $\begin{array}{l}\text { R\&D Institute (B) } \\
\text { (Illustration) }\end{array}$ & $\begin{array}{l}\text { Recreational, e.g., a Club } \\
\text { (C) (Illustration) }\end{array}$ & $\begin{array}{l}\text { Professional Army Unit (D) } \\
\text { (Illustration) }\end{array}$ & $\begin{array}{l}\text { Terrorist Group } \\
\text { (Illustration) (E) }\end{array}$ & $\begin{array}{l}\text { Prison Institution (F) } \\
\text { (Illustration) }\end{array}$ \\
\hline $\begin{array}{l}\text { Group Relations of } \\
\text { Governance, } \\
\text { Leadership and } \\
\text { Reciprocity (V) }\end{array}$ & $\begin{array}{l}\text { Hierarchical social order. } \\
\text { Supervisor planning and } \\
\text { monitoring of production } \\
\text { activities; regulating and } \\
\text { sanctioning inappropriate } \\
\text { deviance }\end{array}$ & $\begin{array}{l}\text { Professional forms of } \\
\text { governance and regulation. } \\
\text { Likely status differences and } \\
\text { symbolic hierarchical order. } \\
\text { Exchange, reciprocity, and } \\
\text { competition more generally. }\end{array}$ & $\begin{array}{l}\text { Minimal formality and } \\
\text { hierarchy but possibly with } \\
\text { status differences. Usually } \\
\text { amicable negotiations and } \\
\text { agreements among } \\
\text { members. Someone or } \\
\text { some members expected to } \\
\text { plan and } \\
\text { coordinate meetings }\end{array}$ & $\begin{array}{l}\text { Strict hierarchy and stringent } \\
\text { monitoring and sanctioning } \\
\text { of behavor. Possibly high } \\
\text { reciprocity and support } \\
\text { among members }\end{array}$ & $\begin{array}{l}\text { Strict hierarchy, } \\
\text { maintenance of sharp } \\
\text { separation among units } \\
\text { (individuals and } \\
\text { subgroups) }\end{array}$ & $\begin{array}{l}\text { Prison leadership and guards } \\
\text { make up an administrative } \\
\text { system. Prisoners form } \\
\text { informal groups for } \\
\text { recreation, illegal activity }\end{array}$ \\
\hline $\begin{array}{l}\text { Production } \\
\text { Functions and } \\
\text { Outputs (VI) }\end{array}$ & $\begin{array}{l}\text { Gaining necessary materials } \\
\text { and technologies. Performing } \\
\text { production and commercial } \\
\text { activities. Achievement of } \\
\text { economic gain from } \\
\text { production and commercial } \\
\text { activities }\end{array}$ & $\begin{array}{l}\text { Gaining necessary materials } \\
\text { and technologies. Performing } \\
\text { research. Initiate and } \\
\text { accomplish potentially } \\
\text { innovative or creative } \\
\text { projects along with } \\
\text { publishing and gaining } \\
\text { scientific recognition } \\
\text { and status. }\end{array}$ & $\begin{array}{l}\text { Gaining access to activity } \\
\text { space, materials, and } \\
\text { technologies for group } \\
\text { activities. For instance, } \\
\text { engagement in particular } \\
\text { sport activities (amateur) }\end{array}$ & $\begin{array}{l}\text { Gaining access to territory, } \\
\text { technologies, and other } \\
\text { materials as well as financing. } \\
\text { Deployment and exercise of } \\
\text { armed force or its threat, for } \\
\text { instance in territorial defense } \\
\text { or offensive action. }\end{array}$ & $\begin{array}{l}\text { Procurement of weapons, } \\
\text { funding, and access to } \\
\text { safe houses. Deployment } \\
\text { and use of terrorist } \\
\text { weapons; action to } \\
\text { conceal identity and } \\
\text { operations. }\end{array}$ & $\begin{array}{l}\text { Prison administration has } \\
\text { prison routines and } \\
\text { technologies (including } \\
\text { weapons) to control } \\
\text { prisoners. Prisoners typically } \\
\text { try to engage in various } \\
\text { illegal or forbidden activities }\end{array}$ \\
\hline $\begin{array}{l}\text { Relations with the } \\
\text { Environment (VII) }\end{array}$ & $\begin{array}{l}\text { Rules and strategies for } \\
\text { dealing with financers, } \\
\text { suppliers, competitors, and } \\
\text { regulators Oriented } \\
\text { dynamically to goods and } \\
\text { services markets. }\end{array}$ & $\begin{array}{l}\text { Rules and strategies for } \\
\text { dealing with funders, } \\
\text { suppliers, competitors, } \\
\text { regulators, and the } \\
\text { professional community. } \\
\text { Strategies vis-à-vis funders, } \\
\text { competitors, relevant } \\
\text { professional communities }\end{array}$ & $\begin{array}{l}\text { Loose boundaries. But } \\
\text { rules and strategies for } \\
\text { dealing with suppliers and } \\
\text { regulators as well as others } \\
\text { in the environment }\end{array}$ & $\begin{array}{l}\text { Strategies for obtaining } \\
\text { essential materials, } \\
\text { technologies and financing. } \\
\text { Dealing with funders, } \\
\text { suppliers, and regulators } \\
\text { Dealing with external } \\
\text { enemies or threats. } \\
\text { Maintaining strict } \\
\text { boundaries. }\end{array}$ & $\begin{array}{l}\text { Dealing with funders and } \\
\text { suppliers as well as with } \\
\text { monitors and potential } \\
\text { observers. Identification } \\
\text { of enemies and targets as } \\
\text { well as threats; } \\
\text { concealment, avoiding } \\
\text { detection and monitoring }\end{array}$ & $\begin{array}{l}\text { Prison administration deals } \\
\text { with funders, suppliers, and } \\
\text { regulators Prison tries to } \\
\text { strictly control prisoner } \\
\text { exchanges with the } \\
\text { environment. }\end{array}$ \\
\hline $\begin{array}{l}\text { Rules and } \\
\text { Procedures for } \\
\text { making or Changing } \\
\text { Rules (VIII) }\end{array}$ & $\begin{array}{l}\text { Dual system. Group } \\
\text { management or higher } \\
\text { management engages in } \\
\text { meta-powering and rule } \\
\text { changing }\end{array}$ & $\begin{array}{l}\text { Flexible, individual choice, or } \\
\text { possible collective choice, } \\
\text { either through multi-actor } \\
\text { negotiation or voting }\end{array}$ & Flexible, Easygoing & $\begin{array}{l}\text { Dual system. } \\
\text { Authoritative-either group } \\
\text { leaders or higher levels make } \\
\text { or change rules. }\end{array}$ & $\begin{array}{l}\text { Dual system. } \\
\text { Authoritative-either } \\
\text { group leaders or superior } \\
\text { levels but highly } \\
\text { clandestine }\end{array}$ & $\begin{array}{l}\text { Dual system. Prison } \\
\text { administration makes and } \\
\text { changes rules (also, from } \\
\text { external law and } \\
\text { policy-making). Prisoners } \\
\text { have their own ways for } \\
\text { making and changing rules, } \\
\text { but typically clandestine }\end{array}$ \\
\hline
\end{tabular}


Table 3. Cont.

\begin{tabular}{|c|c|c|c|c|c|c|}
\hline & $\begin{array}{l}\text { Business Unit (A) } \\
\text { (Illustration) }\end{array}$ & $\begin{array}{l}\text { R\&D Institute (B) } \\
\text { (Illustration) }\end{array}$ & $\begin{array}{l}\text { Recreational, e.g., a Club } \\
\text { (C) (Illustration) }\end{array}$ & $\begin{array}{l}\text { Professional Army Unit (D) } \\
\text { (Illustration) }\end{array}$ & $\begin{array}{l}\text { Terrorist Group } \\
\text { (Illustration) (E) }\end{array}$ & $\begin{array}{l}\text { Prison Institution (F) } \\
\text { (Illustration) }\end{array}$ \\
\hline $\begin{array}{l}\text { Group Resources } \\
\text { (IX) (materials and } \\
\text { technologies). }\end{array}$ & $\begin{array}{l}\text { Specified appropriate } \\
\text { materials, technologies used } \\
\text { in production and } \\
\text { commercial activities; } \\
\text { Sufficient financial resources } \\
\text { (capital) for group } \\
\text { sustainability and } \\
\text { production. }\end{array}$ & $\begin{array}{l}\text { Appropriate resources and } \\
\text { equipment for research and } \\
\text { development in the group's } \\
\text { domain (e.g., computers, } \\
\text { special equipment, programs, } \\
\text { laboratories). } \\
\text { Sufficient funding base is a } \\
\text { critical component of group } \\
\text { knowledge production and } \\
\text { sustainability. }\end{array}$ & $\begin{array}{l}\text { Specified equipment for } \\
\text { activities; access to } \\
\text { activity space }\end{array}$ & $\begin{array}{l}\text { Armaments, military } \\
\text { equipment, access to territory } \\
\text { to locate in. Sufficient } \\
\text { funding to function } \\
\text { effectively relative to real or } \\
\text { potential military challenges }\end{array}$ & $\begin{array}{l}\text { Weapons of destruction; } \\
\text { safe houses. Sufficient } \\
\text { funding to obtain } \\
\text { weapons and to engage } \\
\text { in preparations such as } \\
\text { training and maintaining } \\
\text { save houses and } \\
\text { weaponry. }\end{array}$ & $\begin{array}{l}\text { Prison administration has } \\
\text { substantial resources of } \\
\text { control and sanctioning. } \\
\text { Prisoners have to smuggle in } \\
\text { or to produce themselves } \\
\text { many of their technologies } \\
\text { and other materials }\end{array}$ \\
\hline $\begin{array}{l}\text { Times and Places for } \\
\text { Group Activities (X) }\end{array}$ & $\begin{array}{l}\text { Specified times and places } \\
\text { (factory, office) for } \\
\text { production, bur possibly } \\
\text { with "farming out" and } \\
\text { Flextime-thus likely } \\
\text { fuzziness and variability. }\end{array}$ & $\begin{array}{l}\text { Flexible or loose times and } \\
\text { places for research (work). }\end{array}$ & $\begin{array}{l}\text { Free time of members; } \\
\text { identity of places accessible } \\
\text { to members or the group as } \\
\text { a corporate entity (club). }\end{array}$ & $\begin{array}{l}24-7 \text { readiness, military } \\
\text { camps and offensive and } \\
\text { defensive positions. } \\
\text { Specified territory or } \\
\text { territories for bases. }\end{array}$ & $\begin{array}{l}24-7 \text { readiness. Available } \\
\text { safe group spaces, } \\
\text { training camps }\end{array}$ & $\begin{array}{l}\text { Administration has } 24-7 \\
\text { readiness. Prisoner times and } \\
\text { places decided by prison } \\
\text { administration and/or courts }\end{array}$ \\
\hline
\end{tabular}

Notes: (1) This table concerns rule complexes which, when enacted, generate patterns of group interaction and outcomes/outputs. There is substantial variation in patterns among diverse groups. Such variation is traceable to differences in group rule configurations and in their situational contexts; (2) Note that groups A, B, D, E and F involve task-oriented groups (there are goals, means, specific membership recruitment, governance structures, conceptions and "measures" of success and failure, and reflectivity and, under some conditions, predisposition to reform (see Category VIII)). C, on the other hand, is expressive or "fun" oriented; group activity itself and the experience of pleasure are the aims. However, to engage in a fun activity such as to bowl or to play basketball together, the group has to make arrangements and gain access to, for example, a bowling alley or a basketball court-and dealing with the rules and demands of these facilities becomes a preoccupation or goal consideration (group requisites and derivative goals). Group E (and possibly A, B, and D as well) are task as well as expressive oriented in that there is high emotional involvement of members in productive activities and group matters; (3) A group may undergo changes as a result, for instance, of the development of new goals, new technologies, or new production complexes. Thus, a recreational group might develop a more professional and ultimately business-like orientation with concerns about improved performance, competitivity and obtaining money to finance better technology and qualified participants. Or, an informal research group or network may institutionalize itself within a university, or may establish an independent institute on its own but with appropriate goals about obtaining sustained funding, a physical location and edifice-and, of course, satisfying external requirements for the appropriate features of its organization, membership, and productive activities. Note that time rules in business and research groups have been changing, for instance, more flexible times for group activities (Flextime). Also, space rules are changing with many businesses and research groups as well as military units are globalizing (changing territories and space conditions and rules). Technological systems such as the internet are obviously playing a major role here; (4) For military, prison, and terrorist groups, governance entails hierarchical systems with strict rules of command and obedience. In other words, the rules tend to be stringently applied, monitoring is prison, and terrorist groups, governance entails hierarchical systems with strict rules of command and obedience. In other words, the rules tend to be stringently applied, monitoring is
systematic, and there is considerable disciplinary sanctioning - even substantial internal physical and psychological violence. In research and social play groups, there is more likely to be systematic, and there is considerable disciplinary sanctioning - even substantial internal physical and psychological violence. In research and social play groups, there is more likely to be
rules of collegiality and negotiation for internal governance and the changing or reform of group rules. Business governance operates with hierarchy as well as negotiation forms; physical and even psychological violence tends to be low in many such contexts; (5) Rules concerning the requirements of recruits and participants varies a great deal: To a greater or lesser extent, loyalty to the group and its norms and arrangements is typical of any group. But some groups require high loyalty: for instance, the military and terrorist groups. Merit and skill are important for military, business, and science groups as well as terrorist groups such as Al-Qaeda. 
In the discussion below we focus initially on the "internal coherence" of a single group configuration. The coherence or "logic" relates to the rules of multiple categories fitting together in connection with group purpose, group identity, production functions, roles and role relationships, etc.

The first principle of coherency. The rule content of group rule configurations typically can be characterized by more or less stable, distinct coherencies or logics. In other words, the rules of a configuration are not arbitrarily determined or selected but are required to fit together into a more or less meaningful whole (although at the same time there may be gaps and degrees of inconsistency in rule configurations because the order is a "negotiated order", involving compromises, local adaptations, etc.), it is a historical development. Each of the groups in Table 3 has a more or less coherent rule configuration in the sense that the production functions of the group and its technologies and other resources "fit" or are "appropriate" with respect to the principal group purpose and identity. Similarly, the rules relating to recruitment and involvement of members are also fitting or appropriate in such terms. ${ }^{40}$ And the "place" of group action tends to fit such ends, means, and membership. ${ }^{41}$ In general, there is a patterning or ordering of the universal rule category contents for any given group according to the principle of matching or coherency). ${ }^{42}$

Thus, the rule configuration of the military unit (see Column A in Table 3) consists of specific identity rules as well as rules that articulate group purpose and production functions together with appropriate technologies, recruitment, training, and involvement (skills, loyalties, orientation to authority), authority relations and patterns of governance, and place or location (the rules of these categories relate in expected ways to purpose). ${ }^{43}$ The rule configuration is more or less a coherent package, an identifiable, more or less orderly rule complex. Its coherence and, if you will, its performance effectiveness, varies depending on group tasks, the membership and resource bases and other variables such as the ones suggested below.

Consider a research laboratory, for instance a high-energy lab such as CERN or the Stanford Linear Accelerator (SLAC) (see column D in Table 3). Its identity rules, in addition to name, logo, and location, concern its purpose, its particular research production functions with appropriate technologies, and its rules for recruitment, training, and involvement of participants. Besides permanent scientific leadership and staff, there are selected visitors who come to CERN (or SLAC) to conduct experiments during allocated time periods, they are, in other words, temporary participants in the group, bound to accept the rule regime governing the facility.

In sum, the first principle concerns the coherence or logic of the basic group rule configuration(s). One purpose or function of a coherent group rule configuration entails making group behavior understandable, predictable and controllable in the group domain(s) of activity. It enables predictable coordinated action - and under certain conditions-more effective group actions. However, the level of rule coherence varies depending on the type of group and its main concerns (Burns et al. 2014).

There are multiple coherencies (or incoherencies as the case may be) associated with any rule regime. Other principles of coherence relating to group rule configurations concern the compatibility among multiple regime regimes applying in a group or organization, or the compatibility between a group

40 In most group contexts "fit" or "appropriate" are fuzzy concepts rather than precise or "crisp".

41 What we are doing here may relate to Merton's juxtaposition of values and norms (means) in his famous table of deviance. Of course, he overlooked technologies, time, place, social structure, etc. in his highly abstract characterization.

42 Groups do not establish rule configurations from scratch. They typically make use of "cultural blueprints or algorithms" for setting up a particular group. Of course, the group makes adjustments and adaptations based on the people involved, the context, etc. at the same time there are "family resemblances among the patterns of a certain ideal type of group".

43 Of course, there are odd units that do not fit this pattern very neatly, for instance, "military intelligence", "drone units", "purely administrative staff", etc.- and provide some of the humor as well as challenges to "fit them in" appropriately (see below on multiple logics in groups and organizations). 
configuration (inter-configuration coherence); 44 and the compatibility between a group configuration and external agential and institutional demands deriving from the larger socio-cultural and institutional context.

\subsection{Compatibility of Multiple Group Regimes}

We mentioned earlier that a group may have more than one configuration-which is characteristic of groups or organizations that operate with multiple purposes and production functions, for instance in the case of a group of physicians, which has its professional functions as well as an economic or business function if they operate on a market. These two logics (and possibly more) may operate side-by-side (in a certain sense, parallel and interlinking) or may operate in sequence (phase model) or even in a multi-level fashion (where in case of incompatibility, the higher level process trumps the lower level one), that is, determines the leading or hegemonic rule logic of the complex of multiple rule configurations.

All of our illustrations (Table 3) are ostensibly single logic cases ("ideal types"), but our approach is not limited to such cases and is capable of analyzing groups with multiple group rule configurations or logics, as in the case of a professional group of physicians involved in a private health care market, so that the group operates with a professional configuration as well as a market group configuration; often these are kept distinct through a division of labor, buffering roles between the two domains, and taboos and rituals to prevent or correct any "market pollution" of the professional order (ethos), or any risky subversions of the logic of the market by professional considerations (Machado 1998; Machado and Burns 1998).

Compatibility between a group configuration and the requisites of the larger context. The question is to what extent does the group configuration "fit", or is coherent with, a larger socio-cultural and institutional context, for example, relevant laws and strong societal norms. A group may find one or more rules in its particular rule configuration in contradiction with the demands of external social structures and/or powers. ${ }^{45}$ It may be incapable or unwilling to satisfy specific "performance" demands or legitimation requirements of the regulative environment because doing so would violate rules in its group regime-for instance, professional norms in the case of a professional group or market demands in the case of business enterprises. Neo-institutionalists stress the role of such an environment in constraining and selecting and "reproducing" certain institutional forms, making for greater similarity or convergence of institutional forms than otherwise might be expected. ${ }^{46}$ However, the extent of homogeneity will depend to a greater or lesser extent on the uniformity and force of regulation and on the uniformity and strength of predisposition to compliance among regulated groups (see discussion below concerning deviant behaviour and frontstage and backstage differentiation).

For instance, a medical practice cannot be referred to and operate as a "clinic" unless it meets certain legal, professional, and financial criteria. Similarly, the requisites of legitimation and specific performance demands apply to organizations wishing to be certified as hospitals— they have to provide

44 The stress here is on rule configurations that make sense, and in that respect are considered coherent. But group members typically consider it important for themselves and others that their identity is coherent. They use particular discourses for this purpose. They also make distinctions in their accounts between front-stage and back-stage performances and discourses in order to convey a coherent identity, not one that is fragmented, inappropriate, contradictory, etc. The front-stage and back-stage variants are usually incoherent to a greater or lesser extent.

45 The larger cultural-institutional context may support, for instance, equality, democracy, or secularity, but the group regime is oriented to inequality, extreme authoritarianism, or religious fanaticism, even vicious criminal behavior (or, vice versa, when a democratic group like the Brazilian football team, the Corinthians, after an internal democratization process, decides in the early 1980s to launch a national-wide process that contributed to establishing democracy in Brazil. This became an effective and powerful movement, given the significance of football in Brazil and the national prestige of several of the Corinthians players). Group incoherencies generate the development of front stage-back stage differentiation (see later discussion) but, in some cases, motivates movements to overcome incoherence as in the case of the Corinthians movement in Brazil, striking out at societal tyranny and anti-democratic practices.

46 Illustrations are numerous and diverse: The U.S. Supreme Courts upheld a criminal ban on the use of peyote in Native American sacramental practices. On the other hand, peyote-using groups may maintain a front stage compliance with the law and a backstage violation of the law under conditions where concealment is possible (see later discussion of frontstage and backstage differentiation). 
designated services and maintain certain levels of professional treatment and service. This holds true in a similar fashion in cases of accreditation of a school, college, or university; a "five star" hotel, a "security service", a company or a bank licensed to handle or operate with such dangerous chemicals such as dynamite. The external demands to a greater or lesser extent make for common rule coherency (a major factor in the institutional and cultural context) and the homogeneity of groups operating in a given regulated domain or sector.

To be certified or legitimized in such a context, a group's operating rule regime is expected to satisfy particular criteria and to result in specified performance patterns and practices. Once again, the rule contents of the group configuration are not arbitrary but are "selected" and adapted to satisfy external institutional, legal, and legitimation requisites as well as internal coherence requirements.

Of course, some groups (the proportion varies depending on the field of action and the diverse properties of the groups) do not fit in or conform to environmental demands. They contradict or are incoherent with respect to the environmental legal and normative requisites. This may be because of a lack of sufficient resources, or agential expertise and capabilities, or the pressures to make gains and/or avoid losses through pursuing deviant strategies. This is obvious in the case of a terrorist group (column E in Table 3) but it is also true of apparently legitimate military, business, professional, or research groups that secretly betray their designated purposes and normative requisites. Any of the groups may deviate in some respects from their established "frontstage regime" and, thus, are likely to operate so as to conceal their deviance from authorities and/or publics. ${ }^{47}$ Indeed, such is true of many apparently legitimate enterprises, political parties, professional groups, universities, hospitals, etc. whose operative rule configurations and their actual realizations (that is their "back stage performances") ${ }^{48}$ deviate to a greater or lesser extent from their front stage presentation of self and the ostensible adherence to the laws and norms applying to them (Burns and Flam 1987). Consequently, they operate to conceal their deviant activities and to carefully maintain a front stage/back stage distinction in their behaviour.

The theoretical concepts of multiple group rule configurations and incoherency shed new light on and point to new research questions about differentiation between front stage and back stage (Goffman 1959). In other words, frontstage-backstage differentiation is one form of incoherence between more or less distinct rule configurations, namely that of the frontstage normatively legitimate performance patterns and that of backstage deviation. This is one instance of the general pattern of multiple incoherent but related rule configurations-but where each configuration may be more or less internally coherent. The frontstage rule configuration is one required by law or institutional authorities, at the same time the group operates or tries to operate with a backstage rule configuration that better fits its purpose, limited resources, and/or the local context with its own incompatible pressures.

This pattern of discrepancy between what is legally and/or administratively required in the larger context and the group operative rule configuration and production activities shows up in many

47 The purpose of an ethnically oriented group might be similar to the social group in column B of Table 3, namely to get together to enjoy themselves playing ethnic games, ethnic dancing and singing. But its purpose might also be (or become (under conditions of threat)) to protect or advance the ethnic group (a transition would occur between a purely social group for self-enjoyment and a more militant and outwardly aggressive type group). In the latter case, this may require arming itself, possibly obtaining resources of weapons through criminal means. In this way, they become a multi-logic group. In addition to the logic of an inwardly oriented ethnic group, it develops the logic of an armed group to carry out violence against others as well as to engage in the pursuit of income and other resources through criminal means. These pursuits put them, of course, at odds with the larger society—at the same time their militancy may escalate in response to policing and "repression" from the larger society.

48 There are almost daily revelations about individual and collective agents deviating from legal and normative requirements: In politics, one observes political parties' "dirty tricks", "Watergate" rigged elections; in the corporate world: Enron's bookkeeping fraud, Bernard Madoff's ponzi scheme, Cendant corporation scandal, Bernard Ebbers' WorldCom securities fraud, etc.; Health care: the French blood scandal (HIV contaminated blood), illegal buying and selling of organs for transplantation; cases of euthanasia and mass murders in hospitals; scandals of NGOs, universities, and research institutes in the illegal or improper use of their funds; public and private organizations: release of toxic chemicals, dumping of hazardous wastes, including Love Canal Disaster and innumerable other tragedies, etc. 
forms of group deviance (corruption, unprofessional and unethical behaviour, criminality, etc.). ${ }^{49}$ The concept of rule configuration coherence sheds light not only on frontstage-backstage differentiation but on Goffman's "conman" (Goffman 1959). ${ }^{50}$ He or she (and often there is a group engaged in such systematic deception) constructs and maintains a coherent image vis-à-vis their potential victims (investors, key agents of an enterprise, or wealthy persons). At the same time, con-agents establish and maintain a secret rule configuration known only to themselves, including secret rules of deception, bookkeeping and reporting. Their secret illegal configuration dovetails at key junctures with the frontstage legal version. Money or "real" resource outputs flow into, for instance, their secret accounts-but there is dual and, of course, deceptive bookkeeping: that of the frontstage with virtual accounts and the backstage with more real accounts for use by the "con-group". Particularly interesting from a rule system perspective is that Con-agents require coherent rules in their rule complex used to translate back and forth between the fraudulent system and the legitimizing frontstage system. Of course, the fraudsters keep the translation rules and processes known only to themselves.

The multiple mechanisms structuring group rule configurations point up the importance of an analysis of the process of determining the contents of universal rule categories that make up rule configurations. At the same time, much group rule determination involves compromises-because of internal differences among members but also because of divergence between, on the one hand, internal group rule preferences and, on the other hand, external requirements for group rules and practices.

Our approach alerts one to the fact that multiple mechanisms structure group rule configurations (that is, the selection and determination of their contents). It is not only the group itself which decides on its rules. The multiple and to a certain extent contradictory mechanisms make for incoherencies and compromises of group purposes, norms, production functions, and performances. There are some groups, of course, that operate in minimally regulated spheres or domains (or, are able to effectively avoid through institutionalized powers and/or methods of deception vis-à-vis external constraints and regulation), and they may enjoy considerable freedom and leeway to determine the rule configuration as they wish; this obviously applies to the underground and backstage-oriented groups referred to above.

\subsection{Group Prioritization with Respect to Coherence: Issues of Identity, Social Order, and Its Impact on Performance and Group Outputs}

Why are group actors concerned at all—and to what extent-about the coherence of their rule configurations? A further question relates to the issues about which group actors show the most concern with respect to coherency?

Coherency considerations are most likely in areas where group concerns are high concerning predictability, control/governance and social order: considerations such as, for instance, group identity and status, areas of sacrality, areas of key collective activities and performances, and security. These considerations lead to the articulation of overarching meta-rules which define or assure that the particular rules selected or determined for a rule configuration are appropriate and fitting one another (and fitting

49 Corruption can be treated in this way if there are legal/administrative requisites concerning proper group behaviour. One can speak then of incoherence. But a group configuration might be designed in such a way that some would consider it "corrupt", but the group itself considers the configuration fully appropriate and not discrepant with respect to its own norms, laws, etc. Even in the case there are laws and regulations against some forms of corruption, group members may believe and argue that no one is adhering to the laws and regulations, therefore they are defunct, and thus there is no incoherence between the legal requisites and their own practices. Corruption is the norm in this case.

50 The confidence game entails a ploy confidence people use for obtaining money from one or more persons under false pretences (the exercise of deceit). A "con-person" builds up informal social relationships with roles constructed for the purpose of abusing them; such exploitation is practiced in banks and business organizations by persons who have learned to abuse positions of trust. There are increasing numbers and examples of "conning" through internet presentations of self (Goffman 1959). Goffman (1959, pp. 218-19) points out: we find that confidence men must employ elaborate and meticulous personal fronts and often engineer meticulous social settings, not so much because they lie for a living but because, in order to get away with a lie of that dimension, one must deal with persons who have been and are going to be strangers, and one has to terminate the dealings as quickly as possible. 
other significant rule complexes) and provide sufficient levels of coherence in one or more areas of critical importance.

Of course, some groups have relatively low rule configuration coherence and may show little or no concern about issues of coherency-for reasons identified in the following discussion. However, many groups are highly attentive to these issues; in large part because they concern matters of order and control in areas of major importance to the group.

- Identity and boundary control. If the group is highly concerned about identity issues and, in particular, distinguishing itself from other group(s), then it tries to assure coherence and implementability of recruitment, participation, and performance rules in the rule configuration relating directly (or even indirectly) to group identity. Coherency failure results in ambiguous and confusing identity, status, and performance-for example, instances of group boundary transgression and "pollution". Performances are required to be compatible with or to realize identity.

- The boundary between "the sacred and the profane". In areas of sacrality, a group tries to assure coherence of rule configuration(s) relating to distinctions between the sacred and the profane, and securing the appropriate behavior in relation to these distinctive domains of social action. Incoherence or ambiguity of rules leads to risks of dangerous transgressions and pollution of a sacred area. Violation of rules and rituals that play an important part in distinguishing the sacred from the profane is responded to with fury and even violence.

- Demand for highly effective collective performance. In the cases (see Table 3), the military, ${ }^{51}$ the business unit, $^{52}$ and the terrorist group try to assure coherence among rules so as to assure effective group coordination and collective performance-as they relate to key concerns or purposes of such groups. ${ }^{53}$

- Risky technologies and materials. A group (concerned about its own safety) and/or the external legal and institutional environment demands are oriented to high control of, for instance, risky technology (nuclear power plant, commercial aircraft, high speed trains, etc.), dangerous materials such as hazardous chemicals and explosives. Therefore, it tries to assure appropriate and coherent rules relating directly or indirectly to effective deployment and controlled handling of the risky technologies and materials.

In general, the coherence of a group's rule configuration is essential to group social order: predictability, understandability, and controllability (through rule based controls) of behavior in the group and control over outputs. To varying degrees, groups succeed in establishing and maintaining rule coherency and stringency of implementation for the purposes of reliable performance and predictability - and social order generally—at least in those groups concerned about social order and effective performance relative to their purpose(s) and group requisites. ${ }^{54}$

Established groups tend to develop and operate with a meta-rule or higher level commitment rule which is one of the main bases for selection and coordination of the particular rules of a configuration (such prioritizations are especially noticeable when rule adaptations or changes are necessary) (see later discussion). ${ }^{55}$ Typically, such a meta-rule is associated with group purpose and identity as well as

51 The distinction is found in the differentiation between "battle-ready units" and "barracks units".

52 Of course, the context is important. A business unit in a demanding regulative environment or in a highly competitive environment may be subject to stringency and coherency controls differing significantly from a unit in a far less demanding environment (see later comment on stable and unstable environments).

53 Although a research unit is highly task-oriented and concerned with performance, there may be no overall coordination and regulation, unless it entails a mega-project like the Manhattan Project. There may be, therefore, multiple purposes, diversity in methods and means.

54 Notice that the need to coordinate participants and maintain social order is arguably a more decisive factor in general than technology in determining group social organization (Perrow 1967) (see footnote 34).

55 In times of change, adaptation of some rules or replacement/new selection may be considered necessary, but some changes are typically prioritized over others-in an appropriate or coherent manner. 
effective functioning. ${ }^{56}$ As indicated in Tables $1-3$ as well as Appendix A, identity does not concern only visible symbols but often concerns the special group purpose(s) and means of production and even its internal social structure and governance as well as locations-all playing a part in its "identity complex". In many groups, the meta-rule of coherent design or structuration is embodied in, articulated by, and even imposed by a charismatic or powerful leader-the principal source of "group configuration design"-possibly one external to the group.

Groups may strive for coherence in key areas but fail to achieve it. The world is messy, confusing, difficult to order, because of not fully controllable internal and external forces and dynamics. For instance, regarding key group concerns specified earlier: ${ }^{57}$ Incoherencies increases the likelihood of misperception, confusion, coordination and, in general, governance problems. Examples of group and organizational problems arising from incoherence are discussed and illustrated below.

In sum, what we are claiming is that the characteristic coherence or logic of a group rule configuration is typically motivated by considerations such as identity, sacrality, effective collective action, and security. These need not always be related to ostensibly group purpose(s). However, in any case, such considerations lead to the establishment of overarching meta-rules which are oriented to defining and assuring that the particular rules selected or determined in the rule categories are appropriate for the overall rule configuration and are also appropriate or fitting for one another. However, such aims may fail resulting in cognitive-normative incoherence, confusion, disorder and performance failings. ${ }^{58}$

\section{Linking Group Theory to Social Science Game Theory}

This section links the two theories. The linkage is based on social rule system foundations, which is a cultural-institutional approach to group as well as game conceptualization.

We have identified a particular group subculture-group rule configuration - that characterizes an ideal type or class of groups. The configuration specifies rule regime(s), in particular, norms regarding appropriate members, their roles, group technologies and materials, group settings/places and times, production algorithms, and other group rule complexes (see Figure 2).

56 On the other hand, if the purpose of a given group is to "test" or "find uses for" a particular technology, this would provide the foundation or decisive principle for the group's institutional logic. Perrow (1967) claims a general, decisive role for technology. In our perspective, the rules of group purpose, leadership, and production function are usually more decisive, indeed often determining the criteria for specifying or selecting the technology and other resources. At the same time, once the latter are specified, they play a role in further rule determinations or selections, for instance, where the selection of the place(s) that group operations may be located and the times they may operate. Thus, contrary to Perrow, technology is not consistently a determining factor, although nevertheless an important structuring factor). Notice that the social activity group (column 3 in Table 2) may have decided to get together to bowl or to play pool. Once this choice (the activity and technology) has been decided, however, other determinations follow: where they would getting together, the times for doing this. Therefore, other constraints and constrictions come into play, although the main purpose of the group is simply to get together for sociability and fun.

57 Incoherent group functioning. A highly incoherent group where many of the rules of the group configuration do not fit one another readily-or do not fit the conditions/context of the group, result in decline in capabilities and performance failings. We are so accustomed to some minimum level of coherence, that we can hardly imagine the truly incoherent. But writers and performers do so, for instance Dostoevsky (Crime and Punishment), Kafka (The Process, etc.), the Marx Brothers (they could make their thousands of jokes because of our common understandings of coherence or order-even how particular types of groups should function); the director Tarantino played on this in Pulp Fiction.

58 What can be shown is the problematic nature of incoherence and incompatibilities in rule configurations. Particularly problematic is incompatibility of configurations with respect to group size, technologies, the knowledge and capabilities of group members, group tensions and conflicts, tensions and conflicts with external regimes and/or agents. The result is that members cannot properly or effectively perform norms, roles, production algorithms cannot be properly or effectively performed; there are group and individual performance failures. As a result, pressures and initiatives tend to arise within groups to increase the levels of compatibility—these may or may not lead to improvement. 
GROUP RULE CONFIGURATION (SUBCULTURE)<smiles>[CH]=C</smiles>

RULE REGIME, NORMS, ROLES, PRODUCTION ALGORITHMS,<smiles>[C]=C</smiles>

APPROPRIATE MEMBERS IN

THEIR ROLES \& ROLE RELATIONSHIPS, APPROPRIATE TECHNOLOGIES, MATERIALS, SETTINGS \& TIMES<smiles>C1=CC=C1</smiles>

ACTION \& INTERACTION DETERMINATION

[Rule Following+Decision-making

Generate or Result in Normatively Defined

Patterns of Interaction and Outcomes]<smiles>C1=CC=C1</smiles>

CHARACTERISTIC GROUP GAMES

AND PATTERNS OF SOCIAL ACTION

\& INTERACTION, OUTCOMES/OUTPUTS

Figure 2. Group Rule Configuration and the Structuration of Group Games and Interactions.

Group actors participating in interactions—subject to and regulated by group rule regime(s) generate patterns of interaction and outcome. This occurs in one of the two ways specified in the game theory framework: (I) activity determination entailing following or implementing rules, rule complexes, algorithms, for instance routinized or ritualist role interactions, standard operating procedures (S.O.Ps), etc.; (II) activity determination through game choice and decision-making, that is, a proper game. Games are socially embedded in the group subculture, they tend to be played according to the norms, roles, and other rule complexes characterizing the group rule configuration or sub-culture. For instance, the military unit produces ritual interactions expressing or reinforcing status differences, thus maintaining its internal social order. Also, a business unit generates interactions distinguishing between managers and subordinates, thus maintaining its social order. In both cases, "decision-making" may be involved but the superiors make the decisions and direct subordinates to comply with them (disobedience activates explicit governance processes). Even if a subordinate is ordered or encouraged by a superior to make choices-for instance, to take an initiative, to innovate-the superior is likely to judge whether or not the choice is acceptable (Burns et al. 1985).

As a perusal of Table 3 shows, patterns of activity and interaction are already specified for each of the ideal type of groups. Many of the patterns are routine and entail predictable group behavior. However, the patterns vary substantially among groups-because group sub-cultures (i.e., rule configurations) vary. Factors that play a significant role in differentiating groups are, of course: group identity and purposes, group membership, group production functions or algorithms, and group technologies, as well as such factors as group size. ${ }^{59}$

59 Size and scale are long-recognized factors in social science and sociology. For instance, as a group grows in size, it often will develop at more or less the same time (or, possibly, with a time-lag) appropriate rules and procedures for production functions, internal governance processes, collective decision procedures, etc. 
Multiple factors make for the particular patterns characteristic of a type or class of group. Groups even in the same class or ideal type will differ to a greater or lesser extent because of external/contextual factors (the particular environments in which they function) as well as internal factors (differences in the people participating, their characteristic technologies, their particular production functions and algorithms, their governance and leadership processes, etc.). Thus, although there are rough family resemblances in the groups belonging to an ideal type, the interactions and outcomes vary because of internal and external differences - they can still be systematically compared and analyzed using our framework.

\subsection{Universal Group Games}

While much group behavior is relatively routine and predictable, all functioning or established groups have certain universal games, for instance, collective decision situations that are repeated, more often in some groups than others. That is, bounded free will, collective choice and less than fully predictable behavior occurs. The following is a selection of several such games:

(a) Group collective problem-solving. This concerns non-routine problems which calls for judgment and decision-making in dealing with them. Questions such as the following confront the group: what is the problem? How to deal with it? The problem(s) may be internal ones arising in connection with new members, new leadership, new technologies, changes in resource levels, growth in group size or scale. Or, changes in key external conditions or external agents evokes group decision processes. For instance, external agent(s) on whom the group is dependent ("resource dependency") increase demands in exchange for the resource provided or make additional demands. The group must decide how to react to the demands, for instance, whether or not to accept the demands. Negotiation may ensue, requiring further group decision-making. Radical material change taking place in the environment-flooding, an emerging volcano, or declining food resources (as a result of overhunting or soil salinization) forces the group to abandon the area in order to survive. The group or its leadership makes decisions about departure and where to migrate to.

(b) One universal type of group problem-solving is non-routine conflict-resolution (internal and/or external conflict). Internal conflicts may arise in connection with rivalry among leaders or ongoing hostility between some group members or subgroups. Or, it may involve conflict with external agents. Some sroups establish procedures or mechanisms to resolve non-routine conflicts such as adjudication, negotiation, and democratic vote, which they activate in such situations.

(c) Games about changing rules, policies, paradigms. Functioning or ongoing groups sooner or later engage in games that relate to non-routine changes in group rules and policies as well as entire paradigms. That is, the change is not automatic or algorithmic but involves deliberation and choice. In these situations, there is often a vigorous situational "politics" in the group games to establish, maintain, and change social rules and complexes of rules (in groups as well as organizations and communities). Actors may disagree about, and struggle over, the definition of the situation, and thus over which rule system(s) should apply or how the rule system(s) should be interpreted or applied in the situation. Actors in any group tend to encounter resistance from others when they deviate from or seek to modify established important group rules-or even merely talk about such actions. This sets the stage for games of exercising power either to enforce rules or to resist them, or to introduce new ones. Pressure to change rules and rule complexes may also come from outside the group, for instance external legal requirements or pressures from powerful external agents. Typically, in these cases, the group will try to decide whether to accept the change requirement or oppose it, or accept it "frontstage" but operate clandestinely ("backstage") in opposition to the external demands.

(d) Games about internal and external governance. All functioning groups have such games. These are particularly observable in the case of non-routine deviance or breakdown in group order. 
Some groups have stringent governance, multiple internal controls such as in our illustrative military and terror groups concerning internal behavior such as required manifestations of loyalty and explicit adherence to key norms and role patterns.

(e) Games of Secrecy. All groups have secrets and maintain a frontstage public position as distinct from a backstage group or subgroup position. Much concealment and deception is routine, automatic. Foror non-routine situations, however, there are well-recognized games and strategies around frontstages, back-stages, and their interconnections (Goffman 1959, 1974). Some groups emphasize or exaggerate the distinction between frontstage and backstage, especially if their performance, their freedom, their sustainability depends on concealing illegal activities, inappropriate bership, and forbidden resources and technologies This is particularly important for spy groups or groups engaged in illegal activities (e.g., criminal groups).

\subsection{Differentiation in Rule Configurations and the Definition and Regulation of Games}

Because group sub-cultures (characteristic rule configurations) differ, the norms and other rules that define and regulate the universal games will be different. Differences are suggested by, for instance, the Type V and VIII rule categories-norms governing forms and patterns of leadership and collective decision-making, respectively, for problem-solving and changing rules. A group leader-appointed or elected-may be in a position with (some) group support to change symbols of identity, group purpose or paradigm, its action repertoires, or modalities of collective choice. Or, a group introduces a new technology which calls for new recruitment of people to operate or to maintain the technology; or changes have to be made in performance norms/production algorithms, division of labor, application of norms of distributive justice. Groups with substantial authority and status differentiation tend to organize their universal games accordingly: for instance, the military, terrorist, prison administration, and business groups have authoritative forms for collective decision making to change a rule, role relations, or production algorithms (that is, there are asymmetry rules in contrast to the symmetry assumption of classical game theory). In research groups and many social clubs, the typical form for making decisions is either through multi-agent negotiation and/or democratic procedures (while some form of symmetry obtains, the actual negotiation or democratic forms may differ substantially depending on the particular rule regime and context applying to the group).

\section{Concluding Remarks}

(1) The universal interaction grammar specifies the finite rule categories for all ongoing groups, communities, and organizations. These make up a meta-system. The specific empirical rule content of each and all categories for each group defines the characteristic rule configuration (a specific group "subculture"). That is, a configuration provides key game "rules and rule complexes" for each group. This is the linkage based on social rule system theory between group theory and social science game theory, as we have suggested here.

(2) The group configuration is then a complex of norms and other rules providing a major part of the particular socio-cultural character and "rules of games" (game structures) for the group. Norms of purpose, norms for maintaining/reproducing identity, norms of interaction (authority relations, cooperation, rules of fairness, norms of production/performance (for instance, having fun, producing new scientific or policy knowledge, or norms for doing business and making money and also satisfying clients)). There are also norms for accounting as well as for producing group narratives; norms about appropriate places and times for group activities. Game and interaction outputs—production of patterns are often normative equilibria.

(3) A group or organizational rule configuration coordinates actors, contributes to organizing and regulating them; it enables participants to understand what is going on, who does what (or can do what), how, why, etc. It can be used thus to simulate and to predict (as long as the rule regime continues to be applicable and to function properly); also, the regime provides 
a basis for the asking and giving of group and individual accounts, to criticize and penalize wayward performance and outcomes as well as to praise and reward successful group and individual behavior.

(4) A particular group rule configuration = group subculture = distinct rule regime or norm complex. A configuration has a "cultural logic" or rationality based on the regime organizing and regulating group and individual activities and outputs/outcomes. It contributes to defining a group and differentiating it from other kinds of groups. It contributes to defining types of group interaction situations and their "rules of the game".

(5) All functioning groups have identity rules-at least for referring to and reflecting on group conditions and behavior. For some groups, identity-especially identity contrasted with other competing or conflicting groups-is a major group dimension. While in some groups identity rules and identity are major factors in group life, in many other groups, identity is only a name or symbol for themselves, with no special value attached to the identity, other than their attachments to the group and/or its members.

(6) Norms of cooperation and integration are found to varying degrees in all of the groups in Table 3 (and are typical of most ongoing groups, until conflict or death and disease undermine groupness). The obvious exception in our sample of groups is the "prison social organization" where there are barriers and norms of limited cooperation; there is often even relatively intense enmity between prison guards and prisoners. Cooperation among most members of terrorist groups tend to be highly constrained since cells are meant to be kept secret from the outside world and from one another (as part of their overall clandestine functions).

(7) All groups have to acquire and maintain their material and agential bases (their place(s), particular technologies for group existence, recruitment of new members for purposes of replacement and/or growth, and some level of financing and resource support) Some groups are high-resource consumers (energy, water, land, or financial resources); others require minimal resources for their purposes and activities. This relates, of course, to issues of group vulnerability and sustainability.

Acknowledgments: We are grateful for comments and suggestions relating to this article of Helena Flam as well as two anonymous reviewers.

Author Contributions: Tom R. Burns initiated the preparation of the article. Ewa Roskowska and Tom R. Burns have collaborated on much of the conceptualization, methodology, and applications presented in the paper. Ugo Corte and Nora Machado contributed to extending and elaborating the earlier work and provided literature reviews.

Conflicts of Interest: The authors declare no conflict of interest.

\section{Appendix A. Illustrations of Rules in Rule Categories}

Below we illustrate for each universal rule category some of the rich variation in rule contents, illustrating the diversity of rules making up group rule regimes. As pointed out earlier, rule regimes may or may not be consistently formalized. In addition, the rules include not only directives (normative rules) but also evaluations and value judgments (value rules) and descriptions (descriptive and factual rules, beliefs). Most importantly, the model specifies the universal categories and types of production outputs, but leaves the contents open to group determinations and contextual influences. To a greater or lesser extent, groups themselves determine or select the rule category contents, as illustrated below-but they are often following established designs or prototypes in their fields of action.

\section{Appendix A.1. (I). Group Identity Rules}

Groups are to a greater or lesser extent identified by their purposes, their modus operandi, or some particularities of their rule regimes (reliance on charismatic leadership, extreme coercion, or intense group concern with spirituality and the sacred). In addition, most groups have rules concerning 
concrete identity properties-but again with great variation. Some stress visible symbols: clothes, ${ }^{60}$ hairstyles, tattoos, gestures, speech forms (accents), rituals, and styles of behavior generally. Similarly, particular technologies and material artifacts (rings, lapel pens, the doctor's stethoscope, the bishop's staff) may be emphasized in particular groups, others not. Some groups find the physical structures (built environment) in which they associate or meet essential, yet others do not. Group names may be local, a street or ethnicity area ("Norton Street gang, "Irish Club"), or the name might include a type of task, expertise, or sport. It is not uncommon that the name of a charismatic leader is taken by a group such as "Maoists" and "Peronists." The variation in the content of Category I is very wide-ranging and reflects human imagination and ingenuity.

In sum, identity markers are as much for the members themselves as for "outsiders". At the same time, many particular rules and sub-systems of the group rule-regime may define or contribute to defining a group or constructing its identity, for instance, particular norms and rituals, leadership roles, types of social relationships, characteristics of membership, particular places where the group gathers and the particular times they do it.

\section{Appendix A.2. (II). Membership and Participation/Involvement Rules}

Membership rules (inclusion/exclusion) are a key category of the rule regime. Persons with certain characteristics may be accepted and included as members: for instance, male candidates in the case of all male clubs or female candidates in the case of all female clubs, "Jews" in the case of the Israeli State. These rules specify criteria of recruitment, selection and membership. The criteria may be based, for instance, on gender, ethnicity, religion, education, profession, family or friendship connections, etc. Thus, group recruitment (and "discriminatory" exclusion) may concern religion: no Jews in this group, or no Muslims; similarly for persons because of their educational or professional background. On the other hand, the recruitment rules of the group may be very open to all adults or to large groups of people with certain types of jobs or work experiences, etc. Such differences in recruitment rules establish some of the particularities of the membership base.

Group members are expected to varying degrees to accept and abide by group rules. Involvement concerns motivation, emotion, identification with the group and its agential, rule regime, and social structural features. The number in a group is not critically important except for the small numbers (2, 3, or 5) discussed by Simmel (1898) (but also, see Fine $(2010,2012)$ concerning face-to-face interaction). More important is the varying frequency and qualities (for instance, multi-modal) of interaction which occur even in sizeable communities. Obviously, large-scale groups do not provide opportunities for all members to interact face-to-face, although such a possibility may be a part of "group imagination". Large-scale groups are a particular challenge when it comes to recruitment/involvement and maintaining/reproducing and regulating their agential, resource, and rule regime bases (Burns et al. 2014).

The nature and quality of member involvement in groups varies considerably. Some groups expect and try to enforce strict adherence to group demands, its regime, its leadership (for instance, elite military and police groups, terrorist groups, some extremist religious or political groups); other groups are laissez faire about the stringency and enforcement of some of their standards, norms and roles (at least not the rule complex concerning matters of sacrality), allowing for considerable individual interpretation and choice about the degree and quality of engagement: many clubs, professional associations, and voluntary organizations, among others, provide examples of such laissez faire arrangements. This concerns not only the degree or intensity of emotional and behavioral involvement but the control mechanisms used or applicable. Regime descriptive and normative

60 Some ethnic, religious, professional, and other groups are consistently dressed for public presentation of identity: many Islamic groups, nuns, priests, monks, military, police, etc. 
rules typically specify in the governance function (Category $\mathrm{V}$ rules) the coercive, remunerative, or normative mechanisms (in the latter case, through appealing to particular norms or ideology).

Involvement/participation rules for group members typically correspond to group production rules concerning recruitment and governance (see below). In an agential base, not all "members" need to be fully socialized but non-socialized members must be controlled/controllable so that the group can function properly and effectively.

Typically, there are multiple mechanisms, which motivate/compel members of a group commit themselves to or adhere to the group, its rules, and its leaders. People may be recruited to a technical or scientific group because of the resources provided for the group, or the attraction of the prestige of the group or the high remuneration, or many combinations of these. Often the motivation is over-determined and, therefore, hyper-stable: (i) Strong affinity to the group itself, its leadership, particular members and/or the rule regime; (ii) Identity, status from association with the group, for instance, involvement with a prestigious professional group or group leadership; (iii) Group symbolism and status defines an attractive group and its identity; (iv) common belief, ideology, values fit with the group's image, behavior, and identity ("normative fits"); (v) Ritual processes bind members to the group and to one another and provide experiences of belonging and mutual emotional feelings; (vi) Remuneration: Rewards such as career, respect, good reputation, consideration by others and anticipation of future assistance (that is, potential help), access to group or leader resources, or simply substantial payment. However, also protection from outsiders as well as from some insiders; (vii) The group has strong norms of reciprocity among members (and with the leadership); (viii) Groups produce collective effervescence, creating passion and ecstasy in shared spaces and times, as Durkheim (1976) understood (Fine 2012, p. 166). The challenge is to sustain such emotional attachment in the face of routine and external demands (Fine 2012, p. 166); (ix) Force is deployed in the form of severe physical or psychological punishment, in order to constrain or regulate deviance.

Strength of group ties is a variable stressed by Fine (2010, p. 163) and Granovetter (1985) relating to earlier sociological distinctions between primary groups (strong ties) and secondary groups and networks (weak ties). In our model, the involvement-adherence factor encompasses variables that are a matter of degree. Members' ties (attachments, sentiments) may be to the group as a whole, to its particular rule regime, to its leadership, and/or to particular members. These diverse orientations are often conflated, making a difference in the quality and stability of involvement. For instance, involvement is weakened or collapses for members attached to the particular group leader (a person) when that leader leaves or dies. Similarly, if attachment of some is to particular members, and these drop out, then involvement and commitment to the group is eroded or collapses. Since strength of ties is a matter of degree, and this tends to vary among members, it is a distributed pattern (Hannerz 1992). Groups that consist of members who are attached to the rule regime (group identity, ideology, practices) and to the leadership as well as to many members are involved in a different way and to a different degree than members who are involved because a few of their friends are involved. In groups constructed on the basis of charismatic leadership, members express a form of "love with" the leader.

Most purely task-oriented groups are built not on any attraction or genuine attachments but on remuneration (R) (payment for group involvement and production) or even on coercion (C) (such task-oriented work teams have been constructed and functioned to a greater or lesser extent, as in durable slave systems and in the Nazi and Soviet camps using forced labor). These R-groups and C-groups, respectively, are distinct from affinity groups, A-groups. These are all, however, ideal types. Most functioning groups make use of mixtures of group commitment and social controls.

In general, motives for group involvement may be complex: friendship, status, fun, collective effervescence, normative/spiritual motives. Fine (2012, p. 161) points out that members of, for instance, a religious group may be more oriented to group experiences-increased life satisfaction - than to the religious system of faith (Fine 2012, p. 164) ... "commitment to other seekers is often as powerful—or more so-than one's relationship with the divine" (or the system of belief). As pointed out earlier, the quality and level of adherence and involvement of members varies significantly among groups. 


\section{Appendix A.3. (III). Shared Value Orientations and Ideals}

These rules specify what purposes, values and goals the group and its members are expected to orient toward in the context of group performances and productions. They vary greatly among groups from "having fun" or engaging in a sport, providing mutual psychological or material support, making money/becoming rich, producing new knowledge, helping/serving clients, successfully stealing from or robbing others, defending or "liberating" their community, terrorizing particular groups or communities, or multiples of such value orientations. These values are realized-or implicated-in the production rules and procedures of the group, the division of labor, and the resources mobilized and applied in group performance.

Often, the group itself is highly valued, and its members are expected to treat it with much respect. Groups set value on-and arrange in practice-particular social relations whether hierarchical relations or, on the contrary, egalitarian relations (see category $\mathrm{V}$ below). Also, group values may concern private property-supporting it or possibly opposing it. In the latter case, groups may expect members to share with the group most of what was at one time their private property. A group and its members may value themselves as superior to other groups or populations.

\section{Appendix A.4. (IV). Shared Beliefs and Models of Reality}

Members of a group share beliefs-which are particular rule forms-about, among other things, particular concepts about themselves, others and their social and material environment. In the case it is a professional group, it is likely to see itself as in large part competent and ethical; perhaps, it also sees its clients as genuinely needy, although some of these may be experienced as "difficult", sometimes "ungrateful". Beliefs among many groups concern the environment, whether it is threatening or supportive, whether it can or cannot be changed, and, if changeable, how the group might go about accomplishing change.

\section{Appendix A.5. (V). Social Structural and Relational Rules (Internal Governance)}

Category $(\mathrm{V})$ of the group rule regime defines and regulates relations among group members, their roles and role relationships, norms about reciprocity, competition and conflict.

Groups vary in the degree to which they stress hierarchy (authority, status differentiation) or equality; or the degree of emphasis put on reciprocity and mutual obligations; or the degree of tolerance of deviance or conflict.

(a) What determines the "strength" of the group's social structure-and integration-is the rule regime, group commitment to it, and group control over power resources (in part constituted and regulated by the regime) with which a group social order can be maintained, realized, and reproduced.

(b) What is the appropriate basis of group members to orient to, adhere to, and comply with the rule regime? Above, we identified multiple (often over-determined factors in members' commitment and compliance, although there is variation among members to a greater or lesser extent (Burns 2008)).

(c) Integration of a group may occur because of external threat or challenge which members feel requires cooperation/collaboration to resist or overcome.

(d) When members, particularly key members, lose their orientation and commitment to the group, the group is destabilized and is likely to erode or disintegrate, unless a revitalization is set in motion.

(e) It is not only motivation and adherence which is critical to group order. Group functioning and stability depend on effective coordination, leadership, and conflict resolution as well as maintenance of group agential and resource bases. A group leadership may manage to synthesize or integrate a group as part of its leadership or governance functions. 
(f) Any group may, in general, consist of some degree, even extreme degrees, of weak ties. This is apparent in the case of groups built up on the basis of coercion or employment based on low remuneration and exploitation. Some elements of groupedness (compared to ideal type solidary or strong-tie groups) are missing or undefined.

- In general, in many groups, member commitment to the group, its norms, and its leadership are weak. Indeed, there may be no clarity about who is "controllable" and who is not, who is a genuine member and who is not. Weak-tie groups have weak controls over members, and members have relatively weak controls over one another and over the group as a whole. This makes for feeble and uncertain collective action, mobilization of resources, and effective social control.

- When people from a work place get together for a drink after work, they make up a group of sorts, but the ties are typically weak. Their purpose is none other than socializing. There are weak shared norms and possibly vague role differentiation, but not necessarily friendships or close affinities. Similar observations apply to variation in the degree-of-strength in dyads, triads, etc.

The degree of attraction and integration (strength of ties to the group) may depend on the group's status, power resources, symbols as well as interpersonal links (for instance, a candidate or potential member wants to be in the group and accepts the group's regime because she is friends with or attracted to a key member of the group). Or, she is strongly attracted to the group as a whole and/or to its leader. Hence, those relatively frequent cases of a strongly adherent-committed group membership deriving from a charismatic/attractive leader.

Groups differ significantly in the degree they establish and develop strong ties and patterns of reciprocity and cooperation among members. Our systems model distinguishes between the degree of strength of ties of members to a given group (Granovetter 1973) — "weak-tie groups" and "strong-tie groups" are simply based on a dichotomization of a variable which is a continuum distinguishing groups.

\section{Appendix A.6. (VI). Rules for the Interface with the Environment ("External Governance")}

Production in relation to the larger social and material/ecological environment varies greatly among groups. In general, there are external relations to other groups, networks, and organization, e.g., a work group connects to a professional network, network of suppliers and state agencies, among others.

(a) Boundary maintenance, a key group function, is produced through the effective application of recruitment and involvement rules and through particular strategies of procuring materials and technologies and interacting with the environment.

(b) Groups function in networks and larger organizations as nodes in clusters (Fine 2010). Moreover, these are segments of networks in which weak ties (secondary ties) may be replaced with a set of strong (and intimate) ties (primary). Not all functioning small groups can be characterized by primary ties, as indicated elsewhere in this article.

(c) Powerful groups develop rules and strategies for controlling the environment so as to make it compatible and supportive, enabling group sustainability and evolution. Indeed, given sufficient power, the group changes the environment so "it fits," or "responds to its needs" (Burns and Hall 2012). The possession of such powers, of course, differs greatly among groups.

A group oriented to control or coercive exploitation of its environment would try to acquire or develop the capabilities for such actions-and recruit and involve appropriate members to play the necessary roles and also acquire the appropriate technologies and other resources for such purposes. This would contrast to a group that is oriented to isolating or buffering itself as much as possible 
from its social environment ("withdrawal"), requiring the development of appropriate strategies and capabilities.

\section{Appendix A.7. (VII). Production Rules and Procedures}

Groups regularly produce organized collective action with membership participation, division of labor, leadership, and the deployment of necessary resources. However, they vary greatly in their particular group rule configurations and patterns of symbolic interaction-although their outputs may in some cases be similar.

Rules and rule complex in this category specify how one is to produce (or obtain) specific materials, objects, services, performances, etc. in accordance with particular specifications and standards. The group may produce these for its own use and consumption and/or for external exchange and consumption. Given a group's value orientations, certain productions can be expected: groups oriented to money gains engage in exchange activities from which they expect to make money. "Liberation" groups engage in what they believe are liberating for others, for instance, particular communities and populations to which they are oriented. Terrorist groups produce acts of terrorism directed at meaningful targets in their scheme of things.

Production rules and procedures are designed and implemented on the assumption of appropriate or expected levels of member involvement/engagement. There are often roles designed for purposes of monitoring and regulating group activities and productions (but there are highly integrated groups where all members contribute). Internal governance and regulation are rule based and produced to accomplish group integration, stability, and effectiveness.

In general, groups vary in their production of internal governance, powering and regulatory processes and reciprocity.

(a) Group members translate rule regimes and their rule categories-whose contents vary greatly among groups-into particular interaction patterns, social control and regulation, including the maintenance of role patterns, leadership, and group performances and outputs.

(b) Social control including socialization is based on group specific agential and group procedural mechanisms: forms of recruitment, expulsion, and regulation of role performances (for instance, males and females, leaders and subordinates).

(c) Patterns of agential powering vary among groups. Traditional (conventional) versus formal-legal patterns (in case of registered and publicly legitimized group, e.g., a condominium's self-governance).

(d) There are greater or lesser possibilities for any group member to exercise mutual influence depending on group norms and the rule regime generally.

Appendix A.8. (VIII). Rules and Procedures for Changing Rule Regimes and Group Conditions and Mechanisms

Groups collectively adapt/transform their models, action including production repertoires, value complexes, judgment systems, technologies, and agential base. A group draws on algorithms and heuristics to adapt and innovate producing new agential, rule regime, and resource bases as well as changing/controlling the environment, that is, group circumstances.

Groups provide "cultural arenas" for collective innovation and development, appropriating and interpreting meanings and cultural objects (Fine 2012, p. 318); that is, groups are settings for creation and production of group discourses, reflections, and representations (in part, collective consciousness)

- For example, groups form for the purpose of transforming their status (ethnic or other status enhancement)

- Clubs, gangs, cliques, or other voluntary organizations often have the dual function of providing identity as well as status to members. For example, wearing certain clothes, hats, shoes, hajib, tattoos; eating or not eating certain foods and beverages; participating in certain rituals and ceremonies; 
rejecting association (particularly ritualistic occasions) with members of other groups (again, boundary maintenance)

The adaptation/innovation process may also be facilitated or blocked at the group level-in the latter case reflecting collective inertia, rigidity or ignorance. Groups vary greatly in their subjection to internal and/or external pressures to adapt or innovate and in their willingness or capacity to innovate (see (VI)). What motivates a group to be innovative or creative (prepared to make changes), on the one hand, or oriented to sticking close, conservatively, to the established social order with its routines and rituals, on the other hand. For instance, norms of creativity and innovation are part and parcel of a research group's rule regime/culture, that is, they are institutionalized in the group-possibly in particular roles and sub-groups and their practices. Other groups, for instance, those oriented to producing standardized products (whether goods or services) or those oriented to having "fun and games" tend to acquire or develop other goals and norms, appropriate roles, and practices.

(a) There are internal value and governance mechanisms: in dynamic groups stressing learning, competition, the value of experimentation and innovation, on the one hand, versus those in static groups stressing stability and reproduction, adherence to routines and rituals, and minimization of internal and external competition and conflict.

(b) External processes may produce in most groups' pressures, threats, hazardous events, shocks evoking under some conditions efforts at adaptation and innovation among most groups. The pressures may come, for instance, from natural catastrophes or from the actions or growing threats from established powerful agents or new powerful agents emerging in a group's context.

Appendix A.9. (IX). Technology and Resource Rules.

All groups operate with particular resources, materials as well as technologies. Their resource bases concern the particularities of resources essential to group functioning and performance. Also important are resources available for recruitment purposes, for example, to attract and socialize new members. For instance, a group set up as a science and technology group will not only entail recruitment of appropriate group participants but also appropriate materials and equipment essential to their task. A "street corner gang" interested in sports needs whatever equipment the sport entails and access to or ownership of essential places or built environment of performance. A predatory or defensive gang would need to possess or gain access to appropriate weapons and materials of strategies and actions.

In the past, land and slaves were particularly important as critical resources. In the contemporary world, highly developed technologies, specialized knowledge, and access to critical information are particularly strategic. In any case, groups must obtain necessary resources for group functioning and performance-whether this concerns material resources or particular technologies, knowledge/ expertise, or even legitimacy provided by key agents in the environment:

- Some groups may obtain the resources they require on the basis of property rights or political authority over resources, i.e., rules of access to and use of critical group resources. Other sources of power including normative and coercive capabilities may play a critical role.

- To obtain resources in the environment, groups typically have to deal with agents possessing or controlling access to some of these resources. These activities often entail dealing with external challenges and threats. In general, a group develops external governance strategies and functions for these purposes.

- Collective resources belong to the group-possibly obtained from group members or simply belonging to the group or community (through legal ownership, tradition, exchange, coercion). There are group procedures for deciding how to deploy the resources, for instance, through collective direction (leadership), or collective decision-making, or application of group norms.

- The group itself and its members (or particular members) are themselves key resources-for themselves and their productions including dealing with external agents. 
Appendix A.10. (X). Time and place rules

Groups are distinguishable in terms of their rules about times and places for their activities. For example, the three "text" religions specify different days of worship: Friday (Muslims), Saturday (Jews), Sunday (Christians).

Spatial or domain rules define: Where? Where not? For example, can one set up a market agent in this place? Or initiate in a sacred place here a public debate group? Or is it a space reserved solely for religious practice. Many spaces are "zoned", defining the types of social and other activities such as economic activities which are permitted or forbidden. There may be spaces defined as multi-functional but where usually the functional activities are differentiated in time. For instance, is the time appropriate for the group to engage in a religious, market or other type of social activity? Time rules also indicate when, when not? Or, in more fuzzy terms, "when and where maybe?"

\section{References}

Abell, Peter. 2000. Sociological theory and rational choice theory. The Blackwell Companion to Social Theory 2: $223-44$

Baumgartner, Tom, Tom R. Burns, and Philippe DeVille. 2014. The Shaping of Socio-Economic Systems: The Application of the Theory of Actor-System Dynamics. London: Routledge.

Blau, Peter, and William R. Scott. 1962. Formal Organizations: A Comparative Approach. San Francisco: Chandler Press.

Burns, Tom R. 1990. Models of Social and Market Exchange: Toward a Sociological Theory of Games and Human Interaction. In Structures of Power and Constraint: Essays in Honor of Peter M. Blau. Edited by Craig Calhoun, Michael W. Meyer and William R. Scott. New York: Cambridge University Press.

Burns, Tom R. 2008. Social Rule System Theory: An Overview. In Rule System Theory: Applications and Explorations. Edited by Helena Flam and Marcus Carson. Frankfurt, Oxford and New York: Peter Lang Publishers.

Burns, Tom R., and Philippe DeVille. 2007. Dynamic Systems Theory. In The Handbook of the 21st century Sociology. Edited by Clifton D. Bryant and Dennis L. Peck. Thousand Oaks: Sage Publications.

Burns, Tom R., and Helena Flam. 1987. The Shaping of Social Organizations: Social Rule System Theory and Its Applications. London: Sage Publications.

Burns, Tom R., and Anna Gomolinska. 1998. Modelling Social Game Systems by Rule Complexes. In Rough Sets and Current Tends in Computing. Edited by Lech Polkowski and Andrzej Skowron. Berlin and Heidelberg: Springer.

Burns, Tom R., and Anna Gomolinska. 2000a. The Theory of Socially Embedded Games: The Mathematics of Social Relationships, Rule Complexes, and Action Modalities. Quality and Quantity: International Journal of Methodology 34: 379-406. [CrossRef]

Burns, Tom R., and Anna Gomolinska. 2000b. Socio-cognitive Mechanisms of Belief Change: Applications of Generalized Game Theory to Belief Revision, Social Fabrication, and Self-Fulfilling Prophesy. Cognitive Systems Research 2: 39-54. [CrossRef]

Tom R. Burns, and Peter Hall, eds. 2012. The Meta-Power Paradigm: Structuring Social Systems, Institutional Powers, and Global Contexts. Frankfurt, New York and Oxford: Peter Lang Publishers.

Burns, Tom R., and Ewa Roszkowska. 2001. Fuzzy Game Theory: The Perspective of the General Theory of Games on Nash and Normative Equilibria. In Rough-Neuro Approach: A Way to Computing with Words. Edited by Sankar K. Pal, Lech Polkowski and Andrzej Skowron. Berlin and London: Springer Publishing Company.

Burns, Tom R., and Ewa Roszkowska. 2004. Fuzzy Games and Equilibria: The Perspective of the General Theory of Games. In Rough-Neural Computing: Techniques for Computing with Words. Edited by Sankar K. Pal, Lech Polkowski and Andrzej Skowron. Berlin and London: Springer Publishing Company.

Burns, Tom R., and Ewa Roszkowska. 2005. Generalized Game Theory: Assumptions, Principles, and Elaborations Grounded in Social Theory. Studies in Logic, Grammar, and Rhetoric 8: 7-40.

Burns, Tom R., and Ewa Roszkowska. 2006. Economic and Social Equilibria: The Perspective of GGT. Optimum-Studia Ekonomiczne 3: 1-21.

Burns, Tom R., and Ewa Roszkowska. 2007. Multi-Value Decision-Making and Games: The Perspective of Generalized Game Theory on Social and Psychological Complexity, Contradiction, and Equilibrium. In Festskrift for Milan Zeleny. Amsterdam: IOS Press. 
Burns, Tom R., and Ewa Roszkowska. 2008. The Social Theory of Choice: From Simon and Kahneman-Tversky to GGT Modelling Of Socially Contextualized Decision Situations. Optimum-Studia Ekonomiczne 3: 3-44.

Burns, Tom R., Tom Baumgartner, and Philippe DeVille. 1985. Man, Decisions, Society. London and New York: Gordon and Breach.

Burns, Tom R., Anna Gomolinska, and Loren D. Meeker. 2001. The Theory of Socially Embedded Games: Applications and Extensions to Open and Closed Games. Quality and Quantity: International Journal of Methodology 35: 1-32. [CrossRef]

Burns, Tom R., Jose Caldas, and Ewa Roszkowska. 2005. Generalized Game Theory's Contribution to Multi-agent Modelling: Addressing Problems of Social Regulatiion, Social Order, and Effective Security. In Monitoring, Security and Rescue Techniques in Multiagent Systems. Edited by Barbara Dunin-Keplicz, Andrzej Jankowski, Andrzej Skowron and Marcin Szczuka. Berlin and Heidelberg: Springer.

Burns, Tom R., Ewa Roszkowska, and Nora Machado. 2014. Distributive Justice. Studies in Logic, Grammar, and Rhetoric 37: 11-38. [CrossRef]

Burns, Tom R., Ewa Roszkowska, Ugo Corte, and Nora Machado. 2017. Sociological Approaches to the Reformulation of Game Theory: Models, Comparisons, and Implications of a Social Science Game Theory. Optimum. in press.

Carson, Marcus, Tom R. Burns, and Dolores Gomez Calvo. 2009. Public Policy Paradgims: Theory and Practice of Paradigm Shifts in the European Union. Frankfurt, New York and Oxford: Peter Lang.

Dermott, Terry. 2005. Perfect Soldiers: 9/11 Who They Were, Why They Did It. New York: HarperCollins.

Durkheim, Émile. 1976. The Elementary Forms of the Religious Life. London: Allen and Unwin.

Edling, Christofer R. 2002. Mathematics in sociology. Annual Review of Sociology 28: 197-220. [CrossRef]

Etzioni, Amitai. 1975. Comparative Analysis of Complex Organizations, rev. ed. New York: Free Press.

Fine, Gary A. 2010. The Sociology of the Local: Action and its Publics. Sociological Theory 28: 355-76. [CrossRef]

Fine, Gary A. 2012. Tiny Publics: A Theory of Group Action and Culture. New York: Russell Sage Foundation Publications.

Flam, Helena, and Marcus Carson. 2008. Rule Systems Theory: Applications and Explorations. Frankfurt, New York and Oxford: Peter Lang.

Giddens, Anthony. 1984. The Constitution of Society. Oxford: Polity Press.

Goffman, Erving. 1959. In the Presentation of Self in Everyday Life. London: Penguin.

Goffman, Erving. 1961. Encounters. Indianapolis: Bobbs-Merrill.

Goffman, Erving. 1969. Strategic Interaction. Philadelphia: University of Pennsylvania Press.

Goffman, Erving. 1974. Frame Analysis: An Essay on the Organization of Experience. Cambridge: Harvard University Press.

Gomolinska, Anna. 2002. Derivability of Rules from Rule Complexes. Logic and Logical Philosophy 10: 21-44. [CrossRef]

Gomolinska, Anna. 2005. Towards rough applicability of rules. In Monitoring, Security, and Rescue Techniques in Multiagent Systems. Edited by Barbara Dunin-Kęplicz, Andrzej Jankowski, Andrzej Skowron and Marcin Szczuka. Berlin and Heidelberg: Springer, pp. 203-14.

Gomolinska, Anna. 2008. Rough Rule-Following by Social Agents. In Rule Systems Theory: Applications and Explorations. Edited by Helena Flam and Marcus Carson. Frankfurt, New York and Oxford: Peter Lang.

Gomolinska, Anna. 2010. Satisfiability judgement under incomplete information. Rough Sets XI: Journal Subline of Lecture Notes in Computer Science 5946: 66-91.

Granovetter, Mark S. 1973. The Strength of Weak Ties. American Journal of Sociology 78: 1360-80. [CrossRef]

Granovetter, Mark S. 1985. Economic Action and Social Structure and the Problem of Embeddedness. American Journal of Sociology 91: 481-510. [CrossRef]

Gross, Neil. 2009. A Pragmatist Theory of Social Mechanisms. American Sociological Review 94: 358-79. [CrossRef]

Hannerz, Ulf. 1992. Cultural Complexity: Distributive View of Culture. New York: Columbia University Press.

Harre, Rom. 1979. Social Being. Oxford: Blackwell.

Harre, Rom, and Paul F. Secord. 1972. The Explanation of Social Behavior. Oxford: Blackwell.

Karpik, Leon. 1981. Organizations, Institutions, and History. In Complex Organizations: Critical Perspectives. Edited by Mary Zey-Ferrel and Michael Aiken. Glenview: Scott, Foresman and Company.

Kean, Thomas. 2014. Report of the U.S. National Commission on Terrorist Attacks upon the USA; Washington: Government Printing Office. 
Loia, Vicente, Guiseppe D'Aniello, Angelo Gaeta, and Francisco Orciuoli. 2016. Enforcing situation awareness with granular computing: A systematic overview and new perspectives. Granular Computing 1: 127-43. [CrossRef]

Lotman, Jury. 1975. Theses on the Semiotic Study of Culture. Lisse: Peter de Ridder.

Machado, Nora. 1998. Using the Bodies of the Dead: Legal, Ethical, and Organizations Dimensions of Organ Transplantation. London: Ashgate.

Machado, Nora, and Tom R. Burns. 1998. Complex Social Organization: Multiple Organizing Modes, Structural Incongruence, and Mechanisms of Integration. Public Administration: An International Quarterly 76: 355-86. [CrossRef]

Mirowski, Philip. 1981. Is There a Mathematical NeoinstitutionalEconomics? Journal of Economic Issues 15: 593-613. [CrossRef]

Mirowski, Philip. 1986. The Reconstruction of Economic Theory. Boston and Dordrecht: Kluwer-Nijhoff.

Parsons, Talcott. 1951. The Social System. New York: Free Press.

Perrow, Charles. 1967. A Framework for the Comparative Analysis of Organizations. American Sociological Review 32: 194-208. [CrossRef]

Peterson, Trond. 1994. On the Promise of Game Theory in Sociology. Contemporary Sociology 23: 498-502. [CrossRef]

Posner, Roland. 1989. Toward a Semiotic Explication of Anthropological Concepts. In The Nature of Culture: Proceedings of the International and Interdisciplinary Symposium, Bochum, October 7-ll, 1989. Edited by William A. Koch. Bochum: Studienverlag Dr. Norbert Brockmeyer.

Woody W. Powell, and Paul J. DiMaggio, eds. 1991. The New Institutionalism in Organizational Analysis. Chicago: Chicago University Press.

Roszkowska, Ewa, and Tom R. Burns. 2010. Fuzzy Bargaining Games: Conditions of Agreement, Satisfaction, and Equilibrium. Group Decision and Negotiation 19: 421-40. [CrossRef]

Simmel, Georg. 1898. The Persistence of Social Groups. American Journal of Sociology 3: 662-98. [CrossRef]

Skowron, Andrzej, Andrzej Jankowski, and Samuel Dutta. 2016. Interactive granular computing. Granular Computing 1: 95-113. [CrossRef]

Skowron, Andrzejand, and Andrej Jankowski. 2016. Rough sets and interactive granular computing. Fundamenta Informaticae 147: 371-85. [CrossRef]

Swedberg, Richard. 2001. Sociology and Game Theory: Contemporary and Historical Perspectives. Theory and Society 30: 301-35. [CrossRef]

Wittrock, Bjorn. 1986. Social Knowledge and Public Policy: Eight Models of Interaction. In Social Science and Governmental Institutions. Edited by Charles Weiss and Henry Wollrnan. London: Sage.

Zelizer, Viviena. 2012. How I Became a Relational Economic Sociologist and What Does that Mean. Politics $\mathcal{E}$ Society 40: 145-74.

(C) 2017 by the authors. Licensee MDPI, Basel, Switzerland. This article is an open access article distributed under the terms and conditions of the Creative Commons Attribution (CC BY) license (http://creativecommons.org/licenses/by/4.0/). 